\title{
Demystified...
}

\section{The Epstein-Barr virus and its association with human cancers}

\author{
K R N Baumforth, L S Young, K J Flavell, C Constandinou, P G Murray
}

\begin{abstract}
The Epstein-Barr virus (EBV) has been linked to the development of a variety of human malignancies, including Burkitt's lymphoma, Hodgkin's disease, nasopharyngeal carcinoma, some $T$ cell lymphomas, post-transplant lymphoproliferative disease, and more recently, certain cancers of the stomach and smooth muscle. This review summarises these associations and in particular the role of the viral latent genes in the transformation process.

(F Clin Pathol: Mol Pathol 1999;52:307-322)
\end{abstract}

Keywords: Epstein-Barr virus; Burkitt's lymphoma; Hodgkin's disease; nasopharyngeal carcinoma; $\mathrm{T}$ cell lymphoma; post-transplant lymphoproliferative disease

In 1958, Denis Burkitt, an English surgeon working in Uganda, described a common cancer affecting children in regions of equatorial Africa. The climatic and geographical distribution of Burkitt's lymphoma, as it came to be known, led Burkitt to suggest that a vector borne virus might be responsible. After this, Epstein and his co-workers identified herpesvirus like particles by electron microscopy in a cell line established in culture from a Burkitt's lymphoma biopsy. Subsequently, it was shown that sera from patients with Burkitt's lymphoma had much higher antibody titres to Epstein-Barr virus (EBV) antigens than did controls. As evidence accumulated for the direct involvement of EBV in Burkitt's lymphoma, seroepidemiological evidence also suggested a link between the same virus and undifferentiated nasopharyngeal carcinoma. The detection of EBV DNA in Burkitt's lymphoma and nasopharyngeal carcinoma tumour cells, and the experimental production in 1973 of lymphomas in cotton top marmosets and owl monkeys exposed to EBV, strongly suggested that this virus had oncogenic potential in both human and non-human primates.

Virus and genome structure

EBV is a $\gamma$ herpesvirus and its genome is composed of linear double stranded DNA, approxi-

Accepted for publication 24 August 1999 mately 172 kilobase $(\mathrm{kb})$ pairs in length. EBV has a series of $0.5 \mathrm{~kb}$ terminal direct repeats $(\mathrm{TRs})^{1}$ and internal repeat sequences, ${ }^{2}$ which divide the genome into short and long, largely unique, sequence domains (fig 1). After infection, the TRs join to produce circular (episomal) DNA. Within the terminal repeat sequences, cleavage occurs semi-randomly to produce linear genomes, generated from the same parental template, which differ in their numbers of TRs. When these linear genomes circularise to form episomes, the episomes differ from one another in terms of the number of TRs. In latent infection, the episomes are replicated as episomes and the number of TRs is perpetuated from generation to generation. Separate infectious events, that is, different virions infecting different cells, give rise to latent episomes with varying numbers of TRs. Analysis of TRs is useful in determining the clonality of EBV infected cell populations.

EBV was the first herpesvirus to have its genome cloned and sequenced completely. Because the EBV genome was sequenced from an EBV DNA BamHI fragment cloned library, open reading frames, genes, and sites for transcription or RNA processing are frequently referenced to specific BamHI fragments, from A to $\mathrm{Z}$, in descending order of fragment size (fig 1). Thus, the EBV DNA polymerase gene is referred to as BALF3, indicating that it is the BamHI A fragment, third leftward open reading frame.

\section{The natural history of EBV infection}

EBV infects approximately $95 \%$ of the world's adult population and, after primary infection, the individual remains a lifelong carrier. The oropharynx is the primary site of infection and is believed to be the site for virus replication. ${ }^{3}$ Persistent active lytic infection in this region ensures the production of new virions in the oropharyngeal secretions for transfer in saliva to susceptible hosts. ${ }^{4}$ In underdeveloped countries, primary infection with EBV usually occurs during the 1st few years of life and is often asymptomatic. However, in developed populations, primary infection can often be delayed until adolescence or adulthood, in many cases producing the characteristic clinical features of infectious mononucleosis, including sore throat, fever, malaise, lymphadenopathy, and mild hepatitis. ${ }^{5}$ 
Early in the course of primary infection, $\mathrm{EBV}$ infects $\mathrm{B}$ cells; in vitro, $\mathrm{EBV}$ has been shown to infect $\mathrm{B}$ cells by binding to the CD21 receptor, followed by internalisation of EBV. However, in vivo, it is not known whether primary infection of B cells also involves epithelial cells. ${ }^{6} \mathrm{EBV}$ does not usually replicate in B cells but instead establishes a latent infection. Early in primary infection, EBV infected B cells can be found in large numbers in peripheral blood and tissues. As a consequence of the host immune response, the number of latently infected B cells in the peripheral blood falls to approximately one in $10^{6}$ during the months after primary EBV infection, a pattern that is associated with the alleviation of symptoms.

Several lines of evidence support a role for the B cell as a reservoir of infection, supplying virus to distal epithelial surfaces, or continuously reinfecting the oropharyngeal epithelium. First, the virus has been isolated from several sites that are distant to the oropharynx, including breast milk, semen, and cervical epithelium, ${ }^{8-10}$ suggesting possible carriage of the virus by B cells to these sites. Second, treatment of latently infected individuals with long term acyclovir eliminates virus excretion but does not affect the level of latent infection in B cells. ${ }^{11}$ When treatment is stopped, the virus can be detected in the oropharyngeal secretions at pretreatment levels. ${ }^{12}$ Third, studies of EBV strains in donor-recipient pairs before and after bone marrow transplantation have shown that the recipient's strain disappears from the oropharynx and is replaced by the donor's strain. ${ }^{13}$

\section{In vitro models of $E B V$ infection}

In vitro, EBV readily infects resting peripheral blood B cells that express the EBV receptor, CD21, resulting in latent infection and proliferation. The effect on B cell growth occurs rapidly, with most cells entering DNA synthesis within 48 to 72 hours of EBV infection. ${ }^{14}$ Many of the EBV infected B cells are capable of long term growth in vitro, and cell lines established from these cultures are referred to as lymphoblastoid cell lines. It appears that the original EBV positive B cells are not the source of the lymphoblastoid cell lines, rather that these enter the lytic cycle, generating free virus, which infects other B cells, and these B cells are in fact the source of the lymphoblastoid cell lines. Lymphoblastoid cell lines are not generally permissive for virus production, and of the 80 or so genes present on the viral genome, only a small number of latent genes are expressed, including six nuclear proteins, termed Epstein-Barr virus nuclear antigens (EBNA1, EBNA2, EBNA3A, EBNA3B, EBNA3C, and EBNA leader protein (EBNALP)), the latent membrane proteins (LMP1, LMP2A, and LMP2B), and the Epstein-Barr early RNAs (EBER1 and EBER2). Coordinate expression of these latent genes in infected $\mathrm{B}$ cells leads to a dramatic change in the cellular phenotype, including growth transformation. Lymphoblastoid cell lines also have the ability to form solid tumours when inoculated into nude mouse brain or into the peritoneum of mice with severe combined immunodeficiency (SCID). ${ }^{15}$ Human B cells can also be infected with EBV in vivo in SCID mice. The infected cells are identical in all respects to the lymphoblastoid cell lines generated ex vivo and are also able to grow as solid tumours.

Although most lymphoblastoid cell lines are tightly latent, some contain a small proportion of cells in the lytic cycle. The switch from latency to the lytic cycle is mediated by the BZLF1 and BRLF1 viral transactivator proteins. These proteins trigger a cascade of events, including the sequential expression of numerous "early" and "late" viral genes, and a concomitant downregulation of some latent genes, culminating in cell death and release of infectious virions. Of the lytic cycle genes, the BCRF1 and BHRF1 genes are particularly interesting because they encode homologues of human genes. The BCRF1 gene is expressed late in the lytic cycle and encodes a protein with homology to human interleukin 10 (IL-10). The BCRF1 product is thought to downregulate host immune responses during EBV replication. ${ }^{16}$ BHRF1, also expressed at high levels during the lytic cycle, encodes a BCL-2 like protein, which can protect infected cells from apoptosis. BHRF1 expression has been detected by reverse transcriptase polymerase chain reaction (RT-PCR) in some EBV associated tumours. ${ }^{17}{ }^{18}$

Although EBV DNA is usually present as an episome in latently infected cells, the EBV genome can also persist by integrating into chromosomal DNA or as both integrated and episomal forms. ${ }^{19}$ However, integration is neither chromosome site specific nor a regular feature of EBV infection.

\section{EBV-1 and EBV-2}

Two EBV types infect human populations. These were formerly designated as types $\mathrm{A}$ and $\mathrm{B}$, but are now referred to as EBV-1 and EBV-2. EBV-1 and EBV-2 have extensive homology, except for the regions that encode the EBNAs and the EBERs. EBV-2 transforms B cells less efficiently than does EBV-1, and B lymphocytes infected with EBV-2 in vitro grow less well in reduced serum concentrations and low cell densities, making the establishment of EBV-2 infected cell lines more difficult. The differences in growth characteristics between EBV-1 and EBV-2 infected cells are primarily determined by differences in the EBNA2 coding regions.

In early studies, EBV-2 was more often isolated from the blood of people living in areas where Burkitt's lymphoma and holoendemic malaria were common than from the blood of Western populations. ${ }^{20}$ These results were misleading because they assayed the presence of EBV by establishing spontaneous lymphoblastoid cell lines from donor blood. Because EBV-2 transforms cells less efficiently than EBV-1, these approaches might be expected to miss some people infected with EBV-2. Despite this, subsequent studies have shown that almost half of all African Burkitt's lymphoma tumours carry EBV-2, and EBV-2 DNA is more frequently isolated from the oropharynx 
of people from poorly developed countries. ${ }^{20}{ }^{21}$ Infection with EBV-2 and co-infection with both EBV types is also more common in immunocompromised donors than in the general population. ${ }^{22}$

In addition to the distinction between EBV types, there is also minor heterogeneity within virus types. For example, EBV genomes isolated from nasopharyngeal carcinoma tumours from southern Chinese patients have been shown to contain an additional BamHI restriction site in the $\mathrm{F}$ region. This so called " $f$ " variant was only rarely detected in lymphoblastoid cell lines generated from normal southern Chinese or North American donors, and was suggested to be important in the pathogenesis of nasopharyngeal carcinoma. ${ }^{23}$ However, this form of the virus is not present in nasopharyngeal carcinoma specimens from North Africa, ${ }^{24}$ suggesting that the " $f$ " polymorphism is not necessary for nasopharyngeal carcinoma development. The "f" variant virus appears to have a great affinity for epithelial tissues, ${ }^{25}$ suggesting that virus strains might have evolved that are better suited to infection of different tissues. Variation has also been observed in the LMP1 gene from $\mathrm{EBV}$, including a $30 \mathrm{bp}$ deletion in the C-terminus, which might be important for the transformation effects of this protein (see later). However, the extent to which those genetic variations so far identified are directly responsible for different pathogenic effects or tissue tropisms, or are simply markers of other important genomic changes, remains to be established.

\section{Latent gene function}

At least 11 genes can be expressed during latency and several are implicated in the process of transformation. Each of these is discussed briefly below.

\section{EBNA1}

The EBNA1 gene encodes a DNA binding protein that is essential for replication of the virus within infected cells. EBNA1 is required for the maintenance of latency and the gene is therefore expressed in all forms of viral latency. EBNA1 has also been implicated in the pathogenesis of various EBV associated malignancies, including Burkitt's lymphoma (see below). EBNA1 transgenic mice develop lymphomas, ${ }^{26}$ and antisense inhibition of EBNA1 results in growth inhibition of Burkitt's lymphoma cells in vitro. ${ }^{27}$

EBNA2

The role of EBNA2 in growth transformation was first shown in studies of the EBV infected Burkitt's lymphoma cell line, P3HR-1. The P3HR-1 virus is non-transforming because of a deletion that removes all the EBNA2 coding regions and the last two exons of EBNA-LP. Therefore, EBNA2 must be essential for primary B cell growth transformation-an effect that is mediated by transactivation of other cellular and viral genes. In particular, EBNA2 upregulates the genes encoding CD23, CD21, LMP1, and LMP2 in B cells. ${ }^{28-31}$
EBNA3A, EBNA3B, AND EBNA3C

EBNA3A and EBNA3C are essential for EBV transformation but EBNA3B is not. ${ }^{32}{ }^{33}$ The EBNA3 proteins contain a basic leucine zipper motif, which is homologous to those found in many mammalian transcription factors, although their precise role has yet to be established. EBNA3C has been shown to transactivate some EBNA2 regulated genes, ${ }^{34}$ although it blocks the EBNA2 transactivation of others, including LMP1 and LMP2. ${ }^{35}$

\section{EBNA-LP}

EBV strains that carry mutations in the gene encoding EBNA-LP are partially defective with respect to their ability to immortalise B cells. ${ }^{37}$ EBNA-LP and EBNA2 are the first EBV genes to be expressed after infection of B cells, and they act together to activate cyclin D2 synthesis and hence allow progression of the B cell into the G1 phase of the cell cycle. ${ }^{38}$ EBNA-LP has also been shown to co-localise with the retinoblastoma protein ${ }^{39}$ and the p53 tumour suppresser protein. ${ }^{40}$

LMP1

LMP1 is an integral membrane protein with a molecular weight of approximately $63 \mathrm{kDa}$. It consists of three domains: (1) a 23 amino acid cytoplasmic N-terminus; (2) a 162 amino acid transmembrane domain with six hydrophobic transmembrane segments; (3) a 200 amino acid cytoplasmic C-terminus.

The primary structure of LMP1 shows no appreciable homology to other known mammalian proteins. LMP1 has a very similar localisation and topological structure to certain ion channels and $G$ protein receptors. The topology of LMP1 is shown in fig 2 . As a result of specific proteolytic cleavage (at amino acid 242) LMP1 has a short half life of between two and four hours. The 143 amino acid C-terminal fragment that results from this cleavage is degraded rapidly.

LMP1 is transforming in rodent fibroblast cell lines. ${ }^{41}$ In Rat-1 or NIH 3 T3 cells, LMP1 alters cell morphology and enables cells to

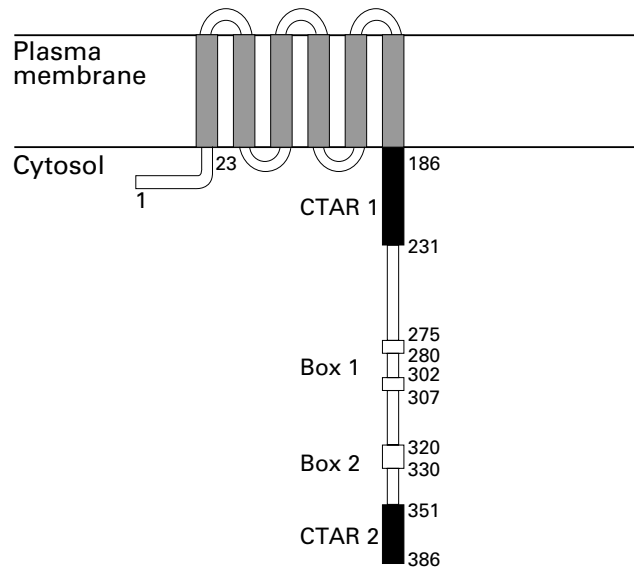

Figure 2 Schematic representation of the latent membrane protein 1 (LMP1) protein of the EBV strain B95.8 with consensus binding sequences. The short cytoplasmic $N$-terminal, six transmembrane domains, and the cytoplasmic $C$-terminus are shown. The two $C$-terminal activating regions (CTAR $1 / 2$, filled rectangles) and box 1 and box 2 motifs (CTAR3, open rectangles) are shown. 


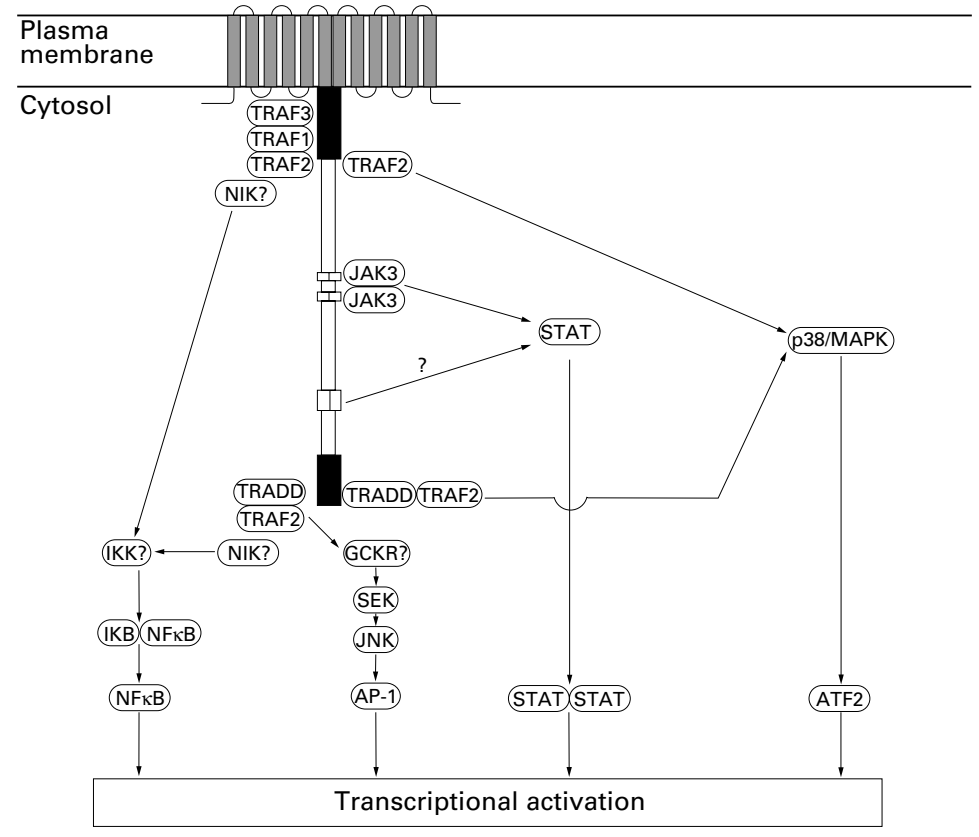

Figure 3 The four pathways by which the EBV latent membrane protein 1 (LMP1) is thought to signal inside cells. LMP1 mediates nuclear factor $\kappa B(N F-\kappa B)$ signalling through both the $C$-terminal activating region 1 (CTAR1) and CTAR2 domains via tumour necrosis factor receptor (TNFR) associated factor (TRAF) molecules. The TNFR associated death domain (TRADD)-TRAF2 complex, which binds to CTAR2, also activates the c-fun $N$-terminal kinase (FNK) $-A P-1$ pathway. Both CTAR1 and CTAR2 use TRAF2 to signal via the p38/MAPK (mitogen activated protein kinase) axis. The recently identified box 1 and box 2 motifs (CTAR3) activate the fanus kinase

( $(A A K)-S T A T$ pathway. The net result of signalling along these pathways is the regulation of transcription of various cellular genes and is responsible for many of the pleiotropic effects of $L M P 1$.

grow in medium supplemented with low serum. ${ }^{41}$ LMP1 also induces loss of contact inhibition in Rat- 1 cells and causes both Rat-1 and $\mathrm{BALB} / \mathrm{c}$ 3T3 cells to lose their anchorage dependence so that they clone with high efficiency in soft agar. ${ }^{42}$ Rat-1 cells expressing LMP1 are tumorigenic in nude mice, whereas control Rat-1 cells are not. ${ }^{41}$ LMP1 expression induces many of the changes associated with EBV infection and activation of primary $B$ cells, including cell clumping; increased cell surface expression of CD23, CD 39, CD40, CD44; decreased expression of CD10; and increased expression of the cell adhesion molecules CD11a (LFA1), CD54 (ICAM1), and CD58 (LFA3). LMP1 has also been shown to protect B cells from apoptosis via the induction of anti-apoptotic proteins, such as BCL-2, MCL-1, and A20. ${ }^{43-45}$ Production of IL- 6 and IL-10 is also induced by LMP1 and might in turn influence inflammatory and immune responses to EBV infection. ${ }^{46-48} \mathrm{LMP} 1$ also affects the growth of epithelial cells, inducing epidermal hyperplasia when produced in the skin of transgenic mice. ${ }^{49}$ In monolayer keratinocyte cultures, LMP1 alters cell morphology and cytokeratin synthesis, and inhibits cell differentiation of immortalised epithelial cells in raft cultures. ${ }^{50} 51$

At least four signalling pathways, namely nuclear factor $\kappa \mathrm{B}(\mathrm{NF}-\kappa \mathrm{B})$, c-Jun N-terminal kinase (JNK)-AP-1, p38/MAPK (mitogen activated protein kinase), and Janus kinase (JAK)-STAT (signal transducers and activators of transcription), are implicated in the function of LMP1 (fig 3). ${ }^{52-55}$ Within the
C-terminus of LMP1 there are at least two activating regions referred to as CTAR 1 and CTAR2 (C-terminal activating region). CTAR1 is located proximal to the membrane (amino acids 186-231) and is essential for EBV mediated transformation of primary B cells. CTAR2 (amino acids 351-386) is located at the extreme C-terminus of LMP1 and is required for long term growth of EBV positive primary B cells. ${ }^{56}$ There are also naturally occurring variants of LMP1 that have a 10 amino acid deletion when compared with the B95.8 prototype strain. ${ }^{58}$ This deletion overlaps CTAR2, and it has been suggested that this variant LMP1 might be more oncogenic than B95.8 LMP1. ${ }^{59}$

Activation of the transcription factor, NF$\kappa \mathrm{B}$, was the first indication of the importance of LMP1 in aberrant cell signalling. Both CTAR1 and CTAR2 can activate NF- $\kappa \mathrm{B}$ independently. ${ }^{52}$ LMP1 deletion mutant studies have shown that CTAR2 accounts for most (70-80\%) of the LMP1 mediated NF- $\mathrm{KB}$ activation via it's interaction with the tumour necrosis factor receptor associated death domain (TRADD) protein. ${ }^{56}$ TRADD normally mediates $\mathrm{NF}-\kappa \mathrm{B}$ signalling from aggregated tumour necrosis factor receptor I (TNFR-I). The last eight amino acids of LMP1 have been shown to be crucial for the interaction of LMP1 with TRADD, although these probably do not define the entire activation site. ${ }^{56}$ The remaining $20-30 \%$ of LMP1 mediated NF- $\mathrm{KB}$ activation is achieved through CTAR1, in particular the $\mathrm{P}^{204} \mathrm{xQ}^{206} \mathrm{xT}^{208}$ motif, which interacts with a number of the TNFR associated factors (TRAFs). ${ }^{60-62}$ The PxQxT TRAF binding motif is also found within the cytoplasmic tails of other TNFR members, including CD30 and CD40.

LMP1 also activates the JNK cascade (also known as the stress activated protein kinase (SAPK) cascade)..$^{53}$ The JNK pathway ultimately leads to the activation of another transcription factor AP-1. Experiments involving transient transfection of LMP1 suggest that LMP1 mediated induction of the transcription factor AP-1 occurs solely through CTAR2. ${ }^{63}$ Stimulation of CD40, TNFR-I, and TNFR-II with appropriate ligand also leads to JNK activation, which is mediated via a TRAF2 dependent pathway. Although apparently similar, the LMP1 mediated NF- $\mathrm{KB}$ and JNK pathways can be dissociated; inhibition of $\mathrm{NF}-\kappa \mathrm{B}$ by a mutated I $\mathrm{B} \alpha$ does not impair LMP1 mediated JNK signalling, whereas expression of a dominant negative stress enhanced kinase (SEK) (c-Jun N-terminal kinase kinase; JNKK), blocks LMP1 mediated JNK signalling but not NF- $\kappa \mathrm{B}$ signalling. ${ }^{53}$

A proline rich sequence within the $33 \mathrm{bp}$ repeat of the LMP1 C-terminus, together with surrounding sequences (between CTAR1 and CTAR2), mediates the activation of JAK3. This proline rich sequence (PxxPxP, amino acids $275-280$ and $302-307$ in the EBV strain B95.8) has been tentatively referred to as CTAR3. The ectopic expression of the genes encoding both LMP1 and JAK3 in 293 cells leads to enhanced tyrosine phosphorylation of 
JAK3 and ultimately to the activation of STAT transcription factors (STAT1 and STAT3). The kinetics of the LMP1 mediated JAK/ STAT pathway appear to be rapid, suggesting that this LMP1 induced pathway precedes both NF- $\mathrm{NB}$ and JNK activation, and might predispose the cell to these later signals. ${ }^{55} \mathrm{~A}$ full review of the structures, signal transduction pathways, and roles in transformation for the JAKs and STATs was published recently. ${ }^{64}$

LMP1 has also been shown to activate the p38/MAPK pathway and hence the transcription factor activating transcription factor 2 (ATF2). The study of LMP1 C-terminal mutants has shown that both the CTAR1 and CTAR2 regions mediate this p38 activation. ${ }^{54}$ To determine the relation between the NF- $\mathrm{NB}$ and p38/MAPK pathways, specific inhibitors of each of the pathways were used. In the presence of an inhibitor of $\mathrm{NF}-\kappa \mathrm{B}$ activation, $\mathrm{p} 38$ activation was not impaired, whereas the use of a p38 inhibitor did not affect NF- $\mathrm{KB}$ binding activity. Therefore, it appears that the LMP1 mediated activation of the p38/MAPK and $\mathrm{NF}-\kappa \mathrm{B}$ pathways occurs independently. However, if TRAF2 is inhibited using a mutant TRAF2 both pathways are blocked, suggesting that the p38/MAPK and $\mathrm{NF}-\kappa \mathrm{B}$ pathways diverge downstream of TRAF $2 .{ }^{54}$

Irrespective of the pathway stimulated by LMP1, aggregation of LMP1 within the plasma membrane is a crucial prerequisite for signalling. LMP1 aggregation appears to be an intrinsic property of the transmembrane domains. ${ }^{65}$ The main difference between LMP1 and the TNFR family is that LMP1 functions as a constitutively activated receptor and, therefore, does not rely on the binding of an extracellular ligand. Experiments that used chimaeric molecules, consisting of the extracellular and transmembrane domains of CD2, CD4, or the nerve growth factor receptor with the cytoplasmic C-terminus of LMP1, proved that LMP1 signalling only occurs upon aggregation of the chimerae via ligand binding or antibody induced aggregation. ${ }^{656}$ Conversely, the CD40 cytoplasmic tail was rendered constitutively active when linked to the $\mathrm{N}$-terminal and transmembrane domains of LMP $1 .{ }^{67}$

LMP2

The LMP2 gene encodes two distinct proteins, LMP2A and LMP2B. The structures of LMP2A and LMP2B are similar; both have 12 transmembrane domains and a 27 amino acid cytoplasmic C-terminus; in addition, LMP2A has a 119 amino acid cytoplasmic N-terminal domain. LMP2A aggregates in patches within the plasma membrane of latently infected $\mathrm{B}$ cells. ${ }^{68}$ LMP2A has effects on signal transduction by obstructing those pathways that are triggered by ligation of the $\mathrm{B}$ cell antigen receptor complex (BCR). Constitutively clustered plasma membrane patches of LMP2A and their associated N-terminal domains mimic crosslinked receptor tails ${ }^{69}$ and become phosphorylated on tyrosine residues. The LMP2A molecules then compete for the binding of proteins with Src homology 2 domains
(SH2), such as the Src family protein tyrosine kinases and the Syk protein tyrosine kinases. ${ }^{70}{ }^{71}$ This blocks signalling through the BCR and prevents transition of the EBV positive $B$ cell into the lytic cycle, thereby maintaining EBV latency. ${ }^{72}$ LMP2B might function by increasing the spacing between LMP2A N-terminals, causing the release of the Src and Syk protein tyrosine kinases and restoring BCR signal transduction.

EBERS

The EBERs are not essential for the transformation of primary B cells by EBV. ${ }^{73}$ EBER1 and EBER2 are small non-polyadenylated RNAs and are the most abundant EBV RNAs in latently infected cells. For this reason the EBERs are used as a marker for the detection of latent EBV infection (see below). The EBERs complex with the La antigen, the ribosomal protein L22, and the interferon inducible protein kinase, $\mathrm{PKR} .{ }^{74-77} \mathrm{PKR}$ plays a role in the antiviral and antiproliferative effects of interferons. The EBERs can inhibit the activation of PKR and, therefore, act in a similar manner to the VA1 and VA2 RNAs of adenoviruses. $^{78}$

\section{Detection of EBV in clinical tissue}

The association between EBV and a range of malignant and non-malignant disorders is now well established. However, the method used to detect the presence of EBV infection may vary between studies, potentially giving rise to variations in the detection rate of the virus within different disease groups. This is best exemplified in Hodgkin's disease, where EBV genomes can be detected in the involved tissues of between $15 \%$ and $41 \%$ of European/USA patients with the disease by means of Southern blotting, ${ }^{7980}$ and a much greater percentage when PCR is applied before Southern blotting. ${ }^{81}$ The use of PCR to detect EBV in Hodgkin's disease has the obvious benefits of ease and sensitivity. However, this exquisite sensitivity increases the likelihood of detecting EBV within non-malignant cells. Therefore, the importance of a positive PCR result when detecting EBV in Hodgkin's disease remains doubtful.

Although the detection of EBV genomes within infected cells can be accomplished with DNA in situ hybridisation methods using BamHI W repeats as a target, such studies have been criticised because of lack of sensitivity and poor signal to noise ratio. The development of an in situ hybridisation method for the abundantly expressed EBERs provided a sensitive method for the detection of latent EBV infection in clinical tissues, including routinely processed histological material (fig 4). ${ }^{82} \mathrm{Be}-$ cause EBERs are believed to be expressed in all forms of viral latency, this provides a consistent marker of latent infection and, perhaps because of the abundance of the EBERs, relatively short hybridisation times usually suffice, providing a technique that can be completed in less than 24 hours. ${ }^{83}$ It is not surprising, therefore, that EBER in situ hybridisation has been used 


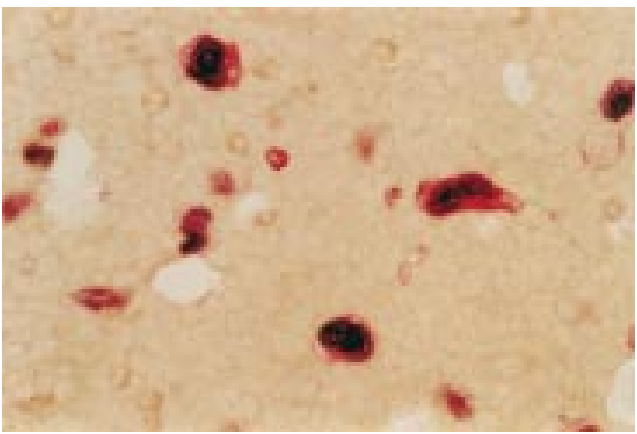

Figure 4 Double labelling for Epstein-Barr virus early RNAs (EBERs) (black/brown) and latent membrane protein 1 (LMP1) (red) in Hodgkin/Reed-Sternberg cells.

extensively in studies demonstrating the association of EBV with a variety of disorders.

The development of a range of monoclonal antibodies directed against latent EBV proteins has also permitted the study of viral gene expression in many of these lesions. In particular, the development of the CS1-4 monoclonal antibody reagent has enabled the detection of the transforming LMP1 protein in EBV associated lymphoproliferative disease, nasopharyngeal carcinoma, and Hodgkin's disease (fig 4), ${ }^{84}$ and has demonstrated its usual absence from others, such as Burkitt's lymphoma. More recently, antibodies to EBNA1, EBNA2, and LMP2 that are effective in routinely processed material have become available. ${ }^{86-90}$

\section{Immunity to EBV in healthy virus carriers}

The presence of EBV in epithelial cells and B cells provokes an intense immune response consisting of antibodies to a large variety of viral antigens. During the acute phase of infectious mononucleosis, the humoral response is directed primarily towards viral antigens of the lytic cycle, notably membrane antigen (MA), early antigen (EA), and viral capsid antigen (VCA) complexes, and is followed by a delayed antibody response to latent antigens, including EBNA1 and EBNA2 ${ }^{91}$ Acute infectious mononucleosis is also characterised by a pronounced IgM antibody response to autoantigens and heterophile antigens, presumably associated with the documented role of the virus as a polyclonal B cell stimulator. As patients with infectious mononucleosis recover from clinical symptoms, the IgM response decreases greatly, whereas the IgG response in serum plateaus at a reduced concentration and is maintained throughout persistent infection. Although the anti-EBNA and anti-VCA responses persist for life, they are thought to have little if any protective role. $^{92}$

The pronounced lymphocytosis of acute infectious mononucleosis provoked an early suspicion that a cellular response might be important in controlling EBV infection. This was reinforced by the observation that many of these atypical lymphocytes are not virus infected $\mathrm{B}$ cells, but $\mathrm{T}$ cells reactive to the viral infection. ${ }^{93}$ Evidence for a specific response against latent infection of $\mathrm{B}$ cells in healthy carriers was provided by the detection of EBV specific memory $\mathrm{T}$ cells through their capacity to regulate the course of virus induced transformation of B cells in vitro. ${ }^{94}$ Thus, when adult donor $\mathrm{T}$ cells are exposed to EBV and placed in culture, the proliferation of virus infected B cells, which occurs within the first two weeks after infection, is followed by a complete regression of growth brought about by cytotoxic T lymphocytes (CTLs) reactivated in vitro. These cells are present only in lymphocyte cultures from EBV seropositive donors and are specific for major histocompatibility complex (MHC) matched EBV infected cells, as demonstrated by their inability to kill autologous mitogen activated blasts. ${ }^{95}$ This CTL response is a classic virus specific response (CD8 positive cells, MHC class I restricted), although EBV specific CD4 positive, MHC class II restricted CTLs have also been described. ${ }^{96}$

In any one individual, EBV specific CTL responses are a composite of reactivities against different viral antigens. Most CTL responses that have been mapped to date are directed towards EBNA3A, EBNA3B, and EBNA3C, whereas CTLs recognising EBNA2, EBNALP, LMP1, and LMP2 appear to be less frequent, and act in the context of a limited number of MHC restrictions. A predominance of responses directed to certain MHC class I-EBV antigen combinations is seen with individuals of similar MHC type. This phenomenon, illustrated by the reactivation of human leucocyte antigen A11 (HLA-A11) restricted CTL memory in virtually all HLA-A11 positive EBV immune white individuals studied to date, ${ }^{97}$ correlates with the recognition of a few immunodominant CTL target epitopes. Several mechanisms could account for the generation of this immunodominance, including differences in the production of antigenic peptides by the cellular processing machinery and the affinity of binding to the presenting MHC class I allele, or individual variations in the $\mathrm{T}$ cell repertoire specific for each epitope. The level of presentation of a given MHCpeptide complex at the surface of EBV infected cells might also be important. ${ }^{98}$

The importance of such immunodominant epitopes in the control of EBV infection is underscored by the finding that two HLA-A11 restricted CTL epitopes, residues 399-408 and 416-424 of the EBNA3B protein, are mutated regularly in EBV strains from south east Asia, where the HLA-A11 allele is expressed in over $50 \%$ of the population. ${ }^{99} 100$ Memory CTL responses specific for the variant epitopes were not detected in HLA-A11 positive Chinese donors infected with the mutated viruses. ${ }^{100}$ Thus, elimination of reactivities to immunodominant CTL epitopes seems to have conferred a selective advantage to the mutated EBV strains in human populations where the relevant restriction element is overrepresented.

CTL responses could potentially be directed against EBV positive malignancies if the tumour cell population expresses the relevant target proteins. EBNA1, expressed in all forms of latent infection, might provide a suitable 
target. However, studies aiming to identify the targets of EBV specific CTLs have so far largely failed to detect EBNA1 specific responses over a wide range of potential MHC class I restrictions. Poor recognition of EBNA1 by cellular immune responses was first seen in experiments performed in an animal model where, in contrast to LMP1, expression of EBNA1 failed to induce rejection of non- immunogenic mammary carcinomas. ${ }^{101}$ Whereas a Gly-Ala repeat domain within the EBNA1 protein is the major target for EBNA specific antibody responses, the unique regions of EBNA1 contain sequences that can be recognised by both polyclonal and clonal CTLs. ${ }^{102} \mathrm{CD} 4$ positive CTL clones have been isolated from healthy seropositive donors that recognise a peptide epitope from EBNA1 in association with HLA-DR $1{ }^{102}$ However, these CTLs were unable to lyse EBV infected cells, suggesting that EBNA1 might not be endogenously processed and/or presented to the CTLs. Although it has been shown that the Gly-Ala repeat region can inhibit endogenous processing and MHC class I presentation, ${ }^{103}$ target cells infected with recombinant vaccinia vectors encoding truncated EBNA1 proteins without the repeat region were also not recognised by these CTL clones. ${ }^{102}$ This Gly-Ala signal might either prevent processing or sequester the processing products to a cellular compartment that is inaccessible to MHC class I presentation. ${ }^{103}$

For malignancies such as Hodgkin's disease and nasopharyngeal carcinoma, CTL responses might target epitopes in LMP1 and LMP2, both of which are expressed by EBV positive tumour cells in these lesions (see below). In one study, in vitro reactivated CTLs were able to recognise a peptide from LMP2A (CLGGLLTMV) restricted through HLA-A2.1. ${ }^{104}$ This CTL response was reactive against a range of virus isolates, including type 1 and type 2 isolates from white, south east Asian, New Guinean, and African individuals. Some of these isolates contained amino acid substitutions within the epitope, but were nevertheless recognised by CTLs raised against B95.8 virus. Other studies have shown that this epitope is the wild type in a small group of EBV associated HLA-A2.1 positive patients with Hodgkin's disease. ${ }^{90}$ In addition, recent studies have shown that the Hodgkin's disease cell line, HDLM2, is able to process and present epitopes from both LMP1 and LMP2 in the context of multiple MHC class I alleles, including HLA-A2, and is sensitive to lysis by EBV specific CTLs. ${ }^{105}$ Furthermore, using autologous fibroblasts infected with a vaccinia recombinant encoding LMP2 as a target, the same authors were able to identify and expand LMP2 specific CTLs from the peripheral blood of a patient with Hodgkin's disease. Such studies might be important for the future development of CTLs for the treatment of EBV associated malignancies.
EBV and lymphoproliferative disease in immunosuppression

The importance of the immune system in suppressing EBV mediated B cell growth and division is underscored by the frequent development of EBV associated lymphoproliferative disease in various immunosuppressive states. The prototypic EBV induced lymphoproliferative disorder arises as a result of the iatrogenic immunosuppression of organ transplant patients, although similar disorders occur in some of the inherited (primary) immunodeficiencies and in patients with AIDS.

Lymphoproliferations that arise after iatrogenic immunosuppression for transplant surgery are virtually always B cell in origin, and are collectively known as post-transplant lymphoproliferative disorders. They comprise a family of lesions ranging from spontaneously regressing atypical polyclonal B cell proliferations to aggressive non-Hodgkin's lymphomas, usually of either diffuse large cell or small non-cleaved cell type. Most lymphoproliferations that arise after solid organ grafts are of host cell origin, whereas those that occur after bone marrow transplantation are often derived from donor cells. In general, most tumours present as multifocal lesions in extranodal locations, such as the gastrointestinal tract or the allograft organ itself.

Although the incidence of post-transplant lymphoproliferative disorder varies with the organ transplanted, the disease is seen with all forms of anti-rejection treatment. The duration of immunosuppression, the dosage, and the number of agents used influence both the risk of post-transplant lymphoproliferative disorder and its clinical pattern. For example, the incidence of this disorder is particularly high after the use of cyclosporine A, and in some series is as high as $15-25 \%$ for cardiac transplant recipients receiving high doses of cyclosporine A. ${ }^{106}$ Cyclosporine $\mathrm{A}$ also shortens the interval between transplantation and the appearance of post-transplant lymphoproliferative disorders. ${ }^{106}$ Similar observations have been made after allogeneic bone marrow transplantation, where these disorders are relatively uncommon $(<1 \%)$, despite the intensive immunosuppression involved. ${ }^{107}$ The use of a monoclonal anti-CD3 antibody (Mab 64.1) was found to be associated with an incidence of post-transplant lymphoproliferative disorders of $14 \%,{ }^{108}$ and $\mathrm{T}$ cell depletion of donor marrow resulted in a $12 \%$ incidence.

Virtually all cases of post-transplant lymphoproliferative disorder are associated with EBV infection, where the virus can be demonstrated within atypical lymphocytes or tumour cells by in situ hybridisation. Regression of posttransplant lymphoproliferative lesions is possible in some cases if immunosuppression is reduced, withdrawn, or the patient infused with EBV specific CTLs generated from the original allogeneic donor. ${ }^{109-112}$ In some cases, CTLs can be used prophylactically in patients at high risk for post-transplant lymphoproliferative disorders. ${ }^{110}{ }^{112}$ Although the association between EBV and post-transplant lymphoproliferative disorders is undisputed, there are 

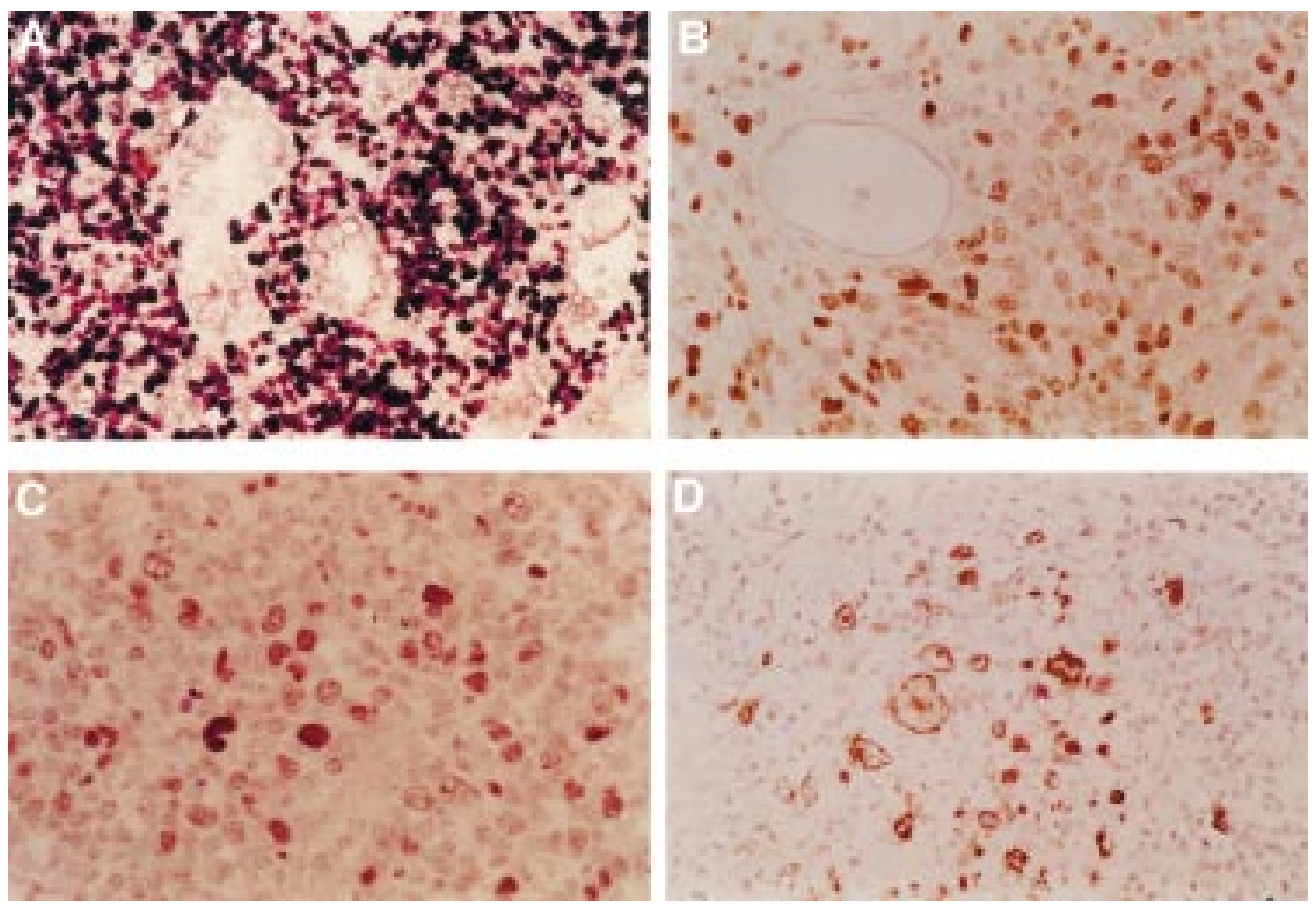

Figure 5 A latency III pattern of gene expression is characteristic of some post-transplant lymphoproliferative lesions. Latency III is characterised by expression of Epstein-Barr virus early RNAs (EBERs) (A), the EBV nuclear proteins, EBNA1 (B) and EBNA2 (C), and latent menbrane protein 1 (LMP1) (D).

conflicting data regarding the expression of latent genes in these disorders. Several initial studies proposed that all post-transplant lymphoproliferative lesions exhibited an unrestricted EBV latent gene expression similar to that seen in lymphoblastoid cell lines (fig 5). ${ }^{113}$ However, more recent studies indicate that the disease is far more heterogeneous with respect to EBV gene expression, and have reported post-transplant lymphoproliferative lesions exhibiting patterns of expression similar to that seen in EBV associated Burkitt's lymphoma (EBNA1 and EBERs alone), or EBV associated Hodgkin's disease and nasopharyngeal carcinoma (EBNA1, EBERs, LMP1, and LMP2). ${ }^{114} 115$ Many post-transplant lymphoproliferative lesions also express the BZLF1 lytic cycle gene, although they are not generally fully permissive for virus production.

It has been suggested that LMP1 gene expression in post-transplant lymphoproliferative disorders might provide an important stimulus in the early development of these lesions. Later, the acquisition of other transforming mutations, such as those affecting the genes encoding $\mathrm{p} 53,{ }^{116} \mathrm{MYC},{ }^{117}$ or BCL-6, ${ }^{118}$ might obviate the need for LMP1 expression. Interestingly, chromosome translocations characteristic of those seen in Burkitt's lymphoma that activate MYC have recently been described in association with LMP1 expression in several post-transplant tumours, ${ }^{119}$ and it has been suggested that these might represent intermediate stages in the development of LMP1 independent lesions. ${ }^{120}$

In many cases, the donor organ itself is the source of EBV infection. In one study, a single organ donor provided a kidney to one patient and a heart-lung block to another. ${ }^{121}$ Both patients developed post-transplant lymphopro- liferative disorders and the virus isolated from the tumours was that of the donor in both instances. Primary EBV infection at the time of, or shortly after, transplant confers an increased risk of post-transplant lymphoproliferative disorder when compared with reactivation of pre-existing infection. ${ }^{122}$

Primary, genetically determined immunodeficiency disorders are a heterogeneous group of syndromes characterised by inherent abnormalities in the development or maintenance of specific immune responses. Lymphoproliferative disorders arising in the primary immunodeficiency syndromes share many of the features of post-transplant lymphoproliferative disorders. They range from polyclonal proliferations of B cells to high grade non-Hodgkin's lymphomas, and also frequently involve extranodal sites. Although EBV is a major cofactor in many of the lymphoproliferative disorders that arise in primary immunodeficiency syndromes, the association is not universal, as is the case with post-transplant lymphoproliferative disorders, and is dependent upon a number of factors, including the nature of the immune defect and the application of immunoreconstitution strategies, such as bone marrow transplantation.

A high frequency of lymphoproliferative disease in human immunodeficiency virus (HIV) infected individuals has been reported since the outbreak of the AIDS epidemic in 1982. In contrast to Kaposi's sarcoma and opportunistic infections, AIDS associated non-Hodgkin's lymphomas are a relatively late manifestation of AIDS, occurring an average of 50 months after HIV infection. Since its initial recognition, the incidence of AIDS associated nonHodgkin's lymphoma has been consistently increasing, and it is now the most frequent HIV 
associated malignancy diagnosed in some HIV risk groups, such as patients with haemophilia. In most cases, AIDS associated non-Hodgkin's lymphomas are derived from B cells, and they display distinctive clinical features, including a widespread extent of disease at presentation, poor prognosis, and the frequent involvement of extranodal sites, with a substantial fraction (between 15\% and 20\%) involving the central nervous system (CNS) as the primary site.

The precise frequency of EBV detection in AIDS associated non-Hodgkin's lymphomas has varied between studies. However, general observations can be made. (1) EBV is present in the tumour cells of virtually all primary AIDS associated non-Hodgkin's lymphomas in the CNS. ${ }^{123}$ (2) Among systemic AIDS associated non-Hodgkin's lymphomas, EBV infection is found in the tumour cells of most diffuse large cell lymphomas, but is restricted to only a fraction $(30-40 \%)$ of the small non-cleaved cell type. (3) Both type 1 and type $2 \mathrm{EBV}$ are frequently detected in AIDS associated nonHodgkin's lymphomas, which contrasts with most cases of EBV positive non-Hodgkin's lymphomas of the immunocompetent host in the Western world, which are generally only infected by type 1 EBV. ${ }^{123} 124$ (4) EBV genomes have been detected in AIDS related body cavity based lymphomas, a rare type of B cell lymphoma. ${ }^{125}$ These tumours also contain Karposi's sarcoma associated herpesvirus (KSHV) DNA; indeed, KSHV might act in conjunction with EBV to induce full transformation in these lesions. ${ }^{125}$

Several observations support the notion that $\mathrm{EBV}$ is important in the pathogenesis of AIDS associated non-Hodgkin's lymphomas. First, it appears that the presence of EBV in the context of persistent generalised lymphadenopathy predisposes to the development of lymphoma, ${ }^{126}$ and, second, using analysis of TRs, EBV infection appears to precede expansion of the tumour clone. Finally, the 100\% association between EBV and HIV related primary CNS lymphomas suggests that EBV might be essential for the development of these tumours.

Overall, EBV gene expression is heterogeneous in AIDS associated non-Hodgkin's lymphoma, with two main patterns occurring within the different pathological types. In the first group, mainly comprising the small non-cleaved cell subtype, EBV infection is limited to expression of EBNA1 and the EBER genes, and LMP1 and EBNA2 are not expressed. ${ }^{127}$ In contrast, most AIDS associated diffuse large cell lymphomas express LMP1 and EBNA2 as well as EBNA1 and the EBER genes, ${ }^{127}$ consistent with the pattern observed in lymphoblastoid cell lines.

\section{Burkitt's lymphoma}

Burkitt's lymphoma was first recognised because of its striking clinical and epidemiological features. The so called "endemic" or high incidence form of Burkitt's lymphoma, which is found at an annual incidence of approximately $5-10$ cases/100 000 children, is restricted to areas of equatorial Africa and Papua
New Guinea, and coincides with areas where infection with Plasmodium falciparum malaria is holoendemic. By contrast, sporadic cases of Burkitt's lymphoma occur worldwide, but at a much lower frequency (at least 50 times lower than in the high incidence areas). The endemic and sporadic forms of Burkitt's lymphoma also differ in their association with EBV. Thus, whereas virtually every Burkitt's lymphoma tumour found in the high incidence regions is EBV positive, only about $15 \%$ of sporadic Burkitt's lymphoma tumours carry the virus. In addition, certain "intermediate incidence" areas outside the regions of holoendemic malaria, such as Algeria and Egypt, have increased numbers of cases that correlate with an increased proportion of EBV positive tumours. A recent study has detected defective integrated EBV genomes without detectable EBNA1 expression in three of nine sporadic Burkitt's lymphoma tumours from the USA. ${ }^{128}$ This suggests greater involvement of the virus in sporadic Burkitt's lymphoma than has been described previously, and indicates a process of viral DNA rearrangement and loss during malignant progression, consistent with a "hit and run" role for EBV in the pathogenesis of Burkitt's lymphoma.

Both endemic and sporadic Burkitt's lymphoma are characterised by chromosome translocations involving chromosome 8 and either chromosome 14, 2, or 22. The most common translocation is the reciprocal $\mathrm{t}(8 ; 14)$, which is present in approximately $80 \%$ of cases, and results in MYC coding sequences being translocated to the immunoglobulin heavy chain constant region. In endemic Burkitt's lymphoma, the breaks in chromosome 8 usually occur outside the MYC locus, and the breaks in chromosome 14 usually occur 5' to, or within, the heavy chain joining region. In sporadic Burkitt's lymphoma, the breaks in chromosome 8 occur either 5 ' to the first non-coding MYC exon, within the first exon, or within the first intron of MYC, and the breaks in chromosome 14 usually occur near the $\mu$ switch region. The break always leaves the second and third MYC coding exons intact. The immunoglobulin heavy chain enhancer is on the reciprocally translocated fragment and thus does not affect MYC gene expression. Rearrangements in the variant $\mathrm{t}(2 ; 8)$ and $\mathrm{t}(8 ; 22)$ translocations usually result in translocation of the light chain genes to a position 3' of the MYC coding sequences, often at distances greater than $50 \mathrm{~kb}$ away. Although variable effects on MYC gene expression have been noted, the prevailing hypothesis is that the translocation leads to deregulated MYC expression, thereby affecting cell proliferation. It has also been shown that there is a significant correlation between the location of the breakpoint on chromosome 8 and the presence or absence of EBV in Burkitt's lymphoma, thus arguing that the EBV positive and negative forms of the tumour have a different molecular mechanism of MYC activation. ${ }^{129}$

In endemic Burkitt's lymphoma, it is thought that EBV and malarial infection together 
stimulate $B$ cell proliferation and thereby increase the probability of one of the specific chromosomal translocations occurring. Malarial infection is known to cause polyclonal activation of $\mathrm{B}$ cells, through the production and release of soluble mitogenic antigens, and a general immunosuppression with impairment of the EBV specific CTL response. The immunosuppressive effects are reflected in an observed fivefold increase in the number of EBV infected $\mathrm{B}$ cells in the systemic circulation during acute malaria ${ }^{130}$ after which, during convalescence, the EBV specific CTL response and the number of EBV infected circulating $B$ cells return to normal values. ${ }^{130}$ In regions where Burkitt's lymphoma is endemic, children may suffer several bouts of acute malarial infection each year before the development of lymphoma.

EBNA1 and the EBERs are the only EBV genes consistently expressed in EBV positive Burkitt's lymphoma tumours, ${ }^{131-133}$ although some reports have documented the expression of LMP1 and EBNA2 in a few tumour cells of some cases of endemic Burkitt's lymphoma, ${ }^{134}$ and LMP1 in several cases of sporadic Burkitt's lymphoma. ${ }^{135}$

Burkitt's lymphoma cells express high levels of the genes encoding CD10 and CD77, a phenotype most closely resembling that of centroblasts in germinal centres. When cells from some EBV positive Burkitt's lymphoma tumours are passaged in culture, the other EBNA and LMP genes are sometimes expressed, and the EBNA2 and LMP1 induced cell surface antigens, such as CD23, CD30, CD39, LFA1, LFA3, and ICAM1, also are upregulated. ${ }^{131}$ EBNA2 and LMP1 are the major mediators of EBV induced B cell growth in vitro, and the lack of expression of the genes encoding these proteins in tumour cells suggests that they are not required for the growth of Burkitt's lymphomas. Altered MYC gene expression might replace EBV driven cell proliferation and allow cells to survive and proliferate with downregulation of the EBNA and LMP genes, which might in turn enable the infected cells to evade CTL immunosurveillance. ${ }^{133}$ This might explain why the drift to a lymphoblastoid cell line phenotype seen in some Burkitt's lymphoma lines in vitro occurs only at a low level in vivo, ${ }^{134}{ }^{135}$ because "drifted" cells would be selectively removed by the CTL response. EBV positive Burkitt's lymphoma lines that have retained the tumour cell phenotype in vitro are not sensitive to lysis by EBV specific CTLs. In addition to the downregulation of the highly immunogenic EBNAs and LMPs, several phenotypic features contribute to reduce the immunogenicity of Burkitt's lymphoma tumour cells. These include reduced expression of cell adhesion molecules, and a general and allele selective downregulation of MHC class I expression. ${ }^{136}$ More recently, defects of antigen processing ${ }^{137}$ and peptide transport ${ }^{138}$ have been shown to promote a general inability of Burkitt's lymphoma cells to present endogenous antigens.

Evidence that EBV and altered MYC gene expression can cooperate to alter B cell growth comes from studies in which EBV was used to transform human B lymphocytes in vitro, followed by the introduction of a rearranged MYC gene, cloned from a Burkitt's lymphoma cell line, into these cells. ${ }^{139}$ Initially, the EBV transformed cells had very low cloning efficiencies in soft agar and did not form tumours in nude mice, but after gene transfer of a rearranged MYC gene, they grew more efficiently in soft agar and were tumorigenic. Activated MYC gene introduced into an EBV transformed cell line in which EBNA2 was rendered oestrogen dependent was shown to induce continuous proliferation of these cells in the absence of functional LMP1 and EBNA2, suggesting that MYC might substitute for LMP1 and EBNA2 in Burkitt's lymphoma progenitor cells. ${ }^{140}$

The form of latency characteristic of Burkitt's lymphoma is often referred to as latency I, to distinguish it from that seen in lymphoblastoid cell lines, which is known as latency III. A further form of latency, referred to as latency II, is characteristic of EBV infection in Hodgkin's disease and nasopharyngeal carcinoma, and is discussed later. Latency I closely resembles the viral status in normal resting $B$ cells, where the EBNA1 and LMP2A genes have been shown to be expressed. ${ }^{141} 142$

Studies on the Akata Burkitt's lymphoma cell line have shown that EBV negative clones can be isolated from the parental EBV positive line after long term culture. ${ }^{143}$ EBV negative and EBV positive clones isolated from the parental line displayed important differences in growth. Thus, in contrast to EBV positive clones, EBV negative cells would not grow in reduced serum conditions or on soft agarose, and were not tumorigenic in nude mice. This indicates that the malignant phenotype of EBV carrying Burkitt's lymphoma might be dependent on the presence of EBV.

\section{Hodgkin's disease}

The first evidence for a possible causal role for EBV in Hodgkin's disease came from the observation that individuals with a history of infectious mononucleosis have a two to threefold increased risk of developing Hodgkin's disease. ${ }^{144}$ Furthermore, raised concentrations of antibodies to VCA and EA have been described in patients with Hodgkin's disease. ${ }^{145}$ Raised concentrations of IgG and IgA antibodies against VCA and EBNA are also associated with a significantly higher relative risk of developing Hodgkin's disease. ${ }^{146}$ However, it has been shown that raised antibody titres to VCA and EA are not predictive of the presence of EBV in Hodgkin/Reed-Sternberg (HRS) cells. ${ }^{147}$

Weiss et al were the first to demonstrate the presence of EBV DNA in Hodgkin's disease tissue specimens using the cloned BamHI W fragment of EBV as an in situ hybridisation probe. ${ }^{148}$ The presence of EBV DNA in Hodgkin's disease tissue and its location in HRS cells was subsequently confirmed by several groups. Initial studies using in situ hybridisation to target the highly abundant EBERs demonstrated EBV in HRS cells in 18-50\% of Hodgkin's 
disease cases. ${ }^{82}{ }^{83}$ However, the frequency of EBV associated Hodgkin's disease cases is much higher in underdeveloped countries such as Peru ${ }^{149}$ and Kenya. ${ }^{150}$

In most cases, type $1 \mathrm{EBV}$ has been detected in Hodgkin's disease tissues, although type 2 virus sequences are found in a lower proportion of cases, and seem to be related to a clinical setting of immunodeficiency. Several investigators have demonstrated the clonality of EBV in Hodgkin's disease tissue by hybridisation with the viral TRs. ${ }^{151}$ These findings indicate clonal expansion of single EBV infected cells and further underline a possible aetiological role of EBV in a proportion of Hodgkin's disease cases.

EBV is not preferentially associated with Hodgkin's disease cases containing immunoglobulin gene rearrangements (that is, of putative B cell origin), but rather is associated with the more aggressive mixed cellularity form of Hodgkin's disease, irrespective of the precise lineage markers expressed on the HRS cells. Immunohistochemical analysis has demonstrated that HRS cells from EBV positive patients have high concentrations of LMP1 in the absence of EBNA2 (latency II pattern) (fig 4). ${ }^{84} 85$ This is supported by transcriptional analysis on fresh biopsies of Hodgkin's disease. ${ }^{152}$

Other studies have suggested that the incidence of EBV positive Hodgkin's disease is age related, with the virus being preferentially associated with tumours from paediatric and older patients. ${ }^{153} 154$ Whereas primary EBV infection might account for the incidence of virus positive Hodgkin's disease cases in the young age group, the association of EBV with the tumour in older patients might reflect increased EBV activity as a result of failing $\mathrm{T}$ cell immunity. In this respect, the overall incidence of Hodgkin's disease is not greatly increased in patients with AIDS, but most Hodgkin's disease tumours arising in such patients are EBV associated. ${ }^{155}$ Recent work has indicated that within the UK, EBV associated Hodgkin's disease is more frequent in individuals living in materially deprived areas. ${ }^{156}$

\section{T cell lymphomas}

EBV has been linked to a proportion of peripheral $\mathrm{T}$ cell non-Hodgkin's lymphomas arising in patients without overt pre-existing immunodeficiency, and to a smaller number of B cell non-Hodgkin's lymphomas arising in such patients. The presence of EBV in high grade $\mathrm{T}$ cell lymphoma has also been shown to be an indicator of poor prognosis. ${ }^{157} \mathrm{~A}$ very high incidence of EBV genomes has been reported in sinonasal $\mathrm{T}$ cell non-Hodgkin's lymphomas occurring in Japanese, Chinese, Peruvian, European, and American patients. It has been suggested that sinonasal $T$ cell non-Hodgkin's lymphomas constitute a distinct clinicopathological entity that is strongly associated with EBV, independently of the racial/geographical distribution. In addition, it has been reported that these lymphomas have peculiar phenotypic and genotypic features, including frequent absence of $\mathrm{T}$ cell antigens, expression of natural killer cell markers, and the absence of $\mathrm{T}$ cell receptor gene rearrangements. The increased incidence of EBV-2 in sinonasal $\mathrm{T}$ cell non-Hodgkin's lymphomas ${ }^{158}$ suggests that occult immunodeficiency might be involved in the pathogenesis of these tumours. Both sinonasal T cell non-Hodgkin's lymphomas and peripheral $\mathrm{T}$ cell lymphomas have been shown to exhibit a latency II pattern.

\section{Nasopharyngeal carcinoma}

An association of EBV with undifferentiated nasopharyngeal carcinomas was suggested as early as 1966 on the grounds of serological studies, and substantiated later by the demonstration of EBV DNA and the EBNA complex in the tumour cells of undifferentiated nasopharyngeal carcinomas by means of in situ hybridisation and anti-complement immunofluorescence. Southern blot hybridisation of DNA from undifferentiated nasopharyngeal carcinoma tissues revealed monoclonality of the resident viral genomes, suggesting that EBV infection had taken place before clonal expansion of the malignant cell population. ${ }^{159}$ Several studies have shown that undifferentiated nasopharyngeal carcinomas are invariably EBV positive, regardless of geographical origin. ${ }^{160-162}$ EBNA1 and the EBER genes are expressed in all EBV positive cases (fig 6), and LMP1 is present in up to $65 \%$ of cases. ${ }^{163} 164$ PCR studies have also revealed expression of the LMP2A and LMP2B genes and of latent transcripts running through the BamHI A region of the EBV genome in the opposite direction to the conventional lytic cycle mRNAs transcribed over this region. ${ }^{165} 166$ These BamHI A transcripts have also been detected in other EBV associated tumours such as Burkitt's lymphoma and Hodgkin's lymphoma. ${ }^{152} 167$

Whereas western blot analysis has suggested a tightly latent EBV infection in undifferentiated nasopharyngeal carcinomas, the expression of BZLF1 has been reported in some cases ${ }^{168}$ although the tumour cells from these carcinomas do not seem to be fully permissive for virus replication. These findings are difficult to reconcile with the frequent detection of antibodies against structural viral proteins in the sera from patients with undifferentiated nasopharyngeal carcinomas. In particular, patients with undifferentiated nasopharyngeal carcinomas have raised IgA antibody titres to the VCA, EA, and MA complexes. The rise in IgA titres to these antigens can be seen several years before the development of undifferentiated nasopharyngeal carcinoma and correlates with tumour burden, remission, and recurrence. ${ }^{169170}$

The association of the other two types of nasopharyngeal carcinoma with EBV is controversial. Viral DNA is detectable in extracts from squamous cell nasopharyngeal carcinomas by Southern blot hybridisation, ${ }^{171}$ although the clonality of the viral episomes could not be ascertained in these cases. Most in situ hybridisation studies have failed to detect EBV DNA or the EBERs in squamous cell nasopharyngeal carcinoma, and PCR only identifies 


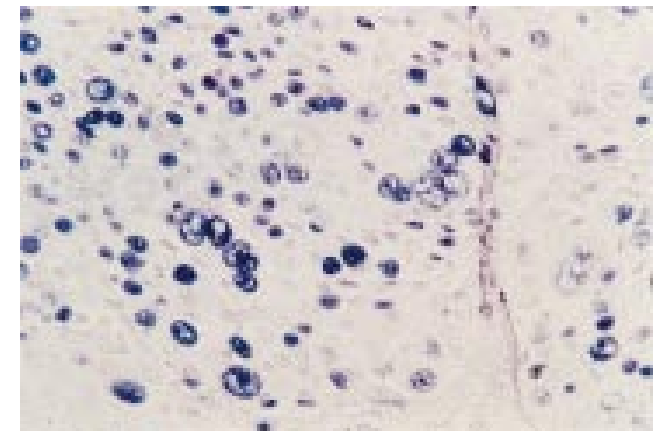

Figure 6 Expression of Epstein-Barr virus early $R N A$ (EBER) genes in undifferentiated nasopharyngeal carcinoma.

EBV DNA in a small proportion of squamous cell nasopharyngeal carcinomas, suggesting that $\mathrm{EBV}$ is present only in reactive $\mathrm{B}$ cells in these lesions. However, a recent report has demonstrated the expression of the EBER genes in all of 31 squamous nasopharyngeal carcinomas. ${ }^{172}$ This apparent conflict might be reconciled by the observation that squamous cell nasopharyngeal carcinomas arising in areas where this carcinoma is endemic are mostly EBV positive, whereas those occurring in areas where nasopharyngeal carcinoma is sporadic are commonly EBV negative. Although EBV infection has been reported in some epithelial dysplastic lesions in the nasopharynx, ${ }^{173}$ and the structure of the EBV terminal fragments indicates that these lesions contain clonal EBV episomes, ${ }^{174} \mathrm{EBV}$ has not been detected in normal nasopharyngeal mucosal biopsies from patients at high risk of developing nasopharyngeal carcinoma, or in normal mucosa adjacent to EBV positive carcinomas at various sites. ${ }^{175}$

The possibility that age at infection or environmental carcinogens might contribute to nasopharyngeal carcinoma was considered in a study comparing the incidence of this malignancy among Cantonese and Malasian individuals living in Singapore. ${ }^{176}$ Both groups were infected at approximately the same age and were living in the same area, yet only the Cantonese individuals developed nasopharyngeal carcinoma. This raised incidence is retained by second generation Chinese individuals who migrate to non-endemic areas. The raised incidence in specific populations suggests that genetic, cultural, or dietary components rather than environmental carcinogens might be important cofactors in nasopharyngeal carcinoma. Exposure to salted fish at an early age has been suggested as one contributing factor and tumour promoting compounds, including nitrosamines, have been identified in food products in areas with a raised incidence. ${ }^{169} 176$

\section{EBV and other cancers}

Carcinomas with similar features to undifferentiated nasopharyngeal carcinomas, undifferentiated carcinomas of nasopharyngeal type, can occur at other sites such as the thymus, tonsils, lungs, stomach, skin, or uterine cervix. The morphological similarities of these two entities have prompted several groups to examine such cases for the presence of EBV. Undifferentiated carcinomas of nasopharyngeal type

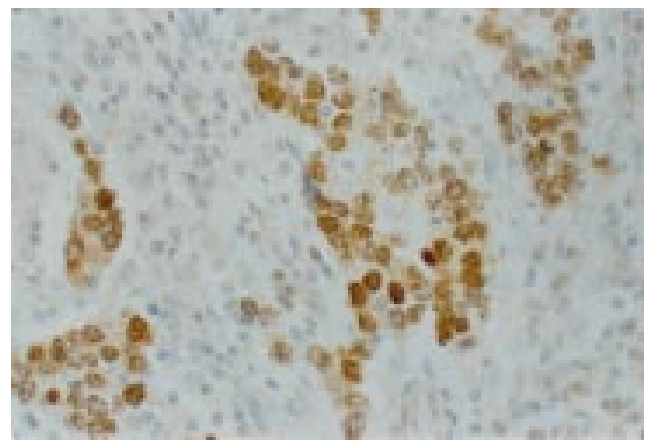

Figure 7 Nuclear expression of the Epstein-Barr virus nuclear antigen 1 (EBNA1) in gastric adenocarcinoma.

of the stomach are consistently EBV positive, irrespective of the geographical origin, whereas the association of the other undifferentiated nasopharyngeal carcinomas with EBV is less strong. EBV has been demonstrated in thymic epithelial tumours from Chinese patients but not Western patients. ${ }^{177}$ Salivary gland undifferentiated carcinomas of nasopharyngeal type are EBV associated in Greenland Eskimos and Chinese but not in white patients, ${ }^{178}$ and several case reports have demonstrated the absence of EBV from these tumours arising in the uterine cervix ${ }^{179}$ and the skin. ${ }^{180} \mathrm{EBV}$ is also found in a small proportion of typical gastric adenocarcinomas of either diffuse or intestinal type (fig 7). However, there is a geographical variation in this association, with the highest rates of virus positive tumours being found in regions of low incidence, such as the USA. ${ }^{181}{ }^{182}$ EBV infection has also been detected in the dysplastic epithelia adjacent to virus positive gastric adenocarcinomas. ${ }^{182}$ Taken together with the finding of monoclonal EBV genomes in gastric cancers, ${ }^{178}$ this suggests that virus infection is an early event in the pathogenesis of these lesions.

In contrast to undifferentiated nasopharyngeal carcinomas, little is known about EBV gene expression in other virus associated carcinomas. A study on salivary gland undifferentiated carcinomas of nasopharyngeal type has revealed a similar pattern to that seen in undifferentiated nasopharyngeal carcinomas. ${ }^{183}$ Immunohistochemical studies of virus associated gastric carcinomas (including both undifferentiated carcinomas of nasopharyngeal type and adenocarcinomas) have shown a restricted pattern of gene expression, limited to the EBERs, EBNA1, and BZLF1, but not LMP1 or the other EBNAs. ${ }^{178} 184185$

Recently, using PCR, Southern blotting, and immunohistochemistry for the EBNA1 protein, the presence of EBV has been detected in a subset of breast cancers ${ }^{186}$. The virus was restricted to tumour cells and was associated more frequently with the most aggressive tumours. Interestingly, the EBERs were not detected. Similar results have been reported recently for hepatocellular carcinoma ${ }^{187}$. Although they require further confirmation, these data suggest that EBV might be a cofactor in some breast and primary liver cancers. 


\section{Conclusion}

The precise mechanisms by which EBV transforms cells are only now being elucidated. Within EBV associated tumours, virus gene expression is limited to a handful of latent genes. Of these, LMP1 has been shown to act as a constitutively activated receptor and to cause aberrant cellular signalling via at least four pathways. This illustrates the complex relation between the virus and the host cell. Knowledge of these processes suggests the existence of potential targets for gene therapy for EBV associated cancers.

1 Given D, Yee D, Griem K, et al. DNA of Epstein-Barr virus: V. Direct repeats of the ends of Epstein-Barr virus DNA. $\mathcal{F}$ Virol 1979;30:852-62.

2 Cheung A, Kieff E. Long internal direct repeat in Epstein-Barr virus DNAs. F Virol 1982;44:286-94.

3 Sixbey JW, Nedrud JG, Raab-Traub N, et al. Epstein-Barr virus replication in oropharyngeal epithelial cells. $N$ Engl $\mathscr{f}$ Med 1984;310:1225-30.

4 Gerber P, Goldstein L, Lucas S, et al. Oral excretion of Epstein-Barr viruses by healthy subjects and patients with infectious mononucleosis. Lancet 1972;2:988-9.

5 Henle G, Henle W, Diehl V. Relation of Burkitt's tumor-associated herpes-type virus to infectious mononucleosis. Proc Natl Acad Sci USA 1968;59:94-101.

6 Rickinson A, Kieff E. Epstein-Barr virus. In: Fields BN, Knipe DM, Howley PM, eds. Fields virology. Philadelphia: Lippincot-Raven, 1996:2397-446.

7 Tosato G, Blaese RM. Epstein-Barr virus infection and Tosato G, Blaese RM. Epstein-Barr virus infection and
immunoregulation in man. Adv Immunol 1985;37:99-149. 8 Israele V, Shirley P, Sixbey JW. Excretion of the EpsteinBarr-virus from the genital tract of men. F Infect Dis 1991 163:1341-3.

9 Junker AK, Thomas EE, Radcliffe A, et al. Epstein-Barr virus shedding in breast milk. Am f Med Sci 1991;302:2203.

10 Sixbey JW, Lemon SM, Pagano JS. A second site for Epstein-Barr virus shedding: the uterine cervix. Lancet 1986;2:1122-4

11 Ernberg I, Andersson J. Acyclovir efficiently inhibits oropharyngeal excretion of Epstein-Barr virus in patients
with acute infectious mononucleosis. F Gen Virol 1986;67: with acute $2267-72$.

12 Yao Q, Ogan P, Rowe M, et al. Epstein-Barr virus infected B cells persist in the circulation of acyclovir-treated virus carriers. Int f Cancer 1989;43:67-71.

13 Gratama JW, Oosterveer MA, Lepoutre JM, et al. Serological and molecular studies of Epstein-Barr virus infection in allogeneic marrow graft recipients [published erratum appears in Transplantation 1990;50:910]. Transplantation 1990;49:725-30. 14 Alfieri C, Birkenbach M, Kieff E. Early events in
Epstein-Barr virus infection of human B-lymphocytes. Virology 1991;181:595-608.

15 Mosier DE, Gulizia RJ, Baird SM, et al. Transfer of a functional human immune system to mice with severe combined immunodeficiency. Nature 1988;335:256-9.

16 Rousset F, Garcia E, Defrance T, et al. Interleukin 10 is a potent growth and differentiation factor for activated
human B lymphocytes. Proc Natl Acad Sci USA 1992;89: 1890-93.

17 Oudejans JJ, van den Brule AJ, Jiwa NM, et al. BHRF1, the Epstein-Barr virus (EBV) homologue of the BCL-2 protooncogene, is transcribed in EBV-associated B-cell lymphomas and in reactive lymphocytes. Blood 1995;86: 1893-902.

18 Jiwa NM, Oudejans JJ, Bai MC, et al. Expression of bcl-2 protein and transcription of the Epstein-Barr virus bcl-2 homologue BHRF-1 in Hodgkin's disease: implications for different pathogenic mechanisms. Histopathology 1995;26: 547-53.

19 Henderson A, Ripley S, Heller M, et al. Human chromosome association of Epstein-Barr virus DNA in a Burkitt tumor cell line and in lymphocytes growth transformed in vitro. Proc Natl Acad Sci USA 1983;80:1987-91.

20 Young LS, Yao QY, Rooney CM, et al. New type B isolates of Epstein-Barr virus from Burkitt's lymphoma and from normal individuals in endemic areas. $\mathcal{F}$ Gen Virol 1987;68: 2853-62.

21 Sixbey JW, Shirley P, Chesney PJ, et al. Detection of a second widespread strain of Epstein-Barr virus. Lance 1989;2:761-5.

22 Borisch B, Finke J, Hennig I, et al. Distribution and localization of Epstein-Barr virus subtypes A and B in AIDSrelated lymphomas and lymphatic tissue of HIV-positive patients. F Pathol 1992;168:229-36.

23 Lung ML, Chang GC, Miller TR, et al. Genotypic analysis of Epstein-Barr virus isolates associated with nasopharyngeal carcinoma in Chinese immigrants to the United States. Int 7 Cancer 1994;59:743-6.

24 Bouzid M, Djennaoui D, Dubreuil J, et al. Epstein-Barr virus genomes in NPC biopsies from North Africa. Int $\mathscr{f}$ Cancer 1994;56:468-73.
25 Lung ML, Lam WP, Chan KH, et al. Direct detection of Epstein-Barr virus in peripheral blood and comparison of EBV genotype present in direct specimens and lymphoblastoid cell lines established from nasopharyngeal carci-
noma patients and healthy carriers in Hong Kong. Int $\mathcal{F}$ noma patients and hea

26 Wilson JB, Bell JL, Levine AJ. Expression of Epstein-Barr virus nuclear antigen-1 induces $\mathrm{B}$ cell neoplasia in transgenic mice. EMBO f 1996;15:3117-26

27 Magrath I, Jain V, Bhatia K. Molecular epidemiology of Burkitt's lymphoma. The Epstein-Barr Virus and Associated Diseases 1993;225:377.

28 Abbot SD, Rowe M, Cadwallader K, et al. Epstein-Barr virus nuclear antigen 2 induces expression of the virus-encod

29 Wang F, Gregory CD, Rowe M, et al. Epstein-Barr virus nuclear antigen 2 specifically induces expression of the Buclear antigen 2 specifically induces expression of the 1987;83:3452-7.

30 Wang F, Tsang S, Kurila M, et al. Epstein-Barr virus nuclear antigen 2 transactivates the latent membrane protein (LMP1). F Virol 1990;64:3407-16.

31 Zimber-Strobl U, Suentzenich KO, Laux G, et al. EpsteinBarr virus nuclear antigen 2 activates transcription of the terminal protein gene. F Virol 1991;65:415-23

32 Tomkinson B, Kieff E. Use of second-site homologous recombination to demonstrate that Epstein-Barr virus nuclear protein 3B is not important for lymphocyte infection or growth transformation in-vitro. $f$ Virol 1992;66:2893-903.

33 Tomkinson B, Robertson E, Kieff, E. Epstein-Barr virus nuclear proteins EBNA-3A and EBNA-3C are essential for B-lymphocyte growth transformation. F Virol 1993;67: 2014-25.

34 Wang F, Gregory C, Sample C, et al. Epstein-Barr virus latent membrane protein 1 (LMP1) and nuclear proteins 2 and 3C are effectors of phenotypic changes in B-lymphocytes: EBNA2 and LMP1 cooperatively induce CD23. F Virol 1990;64:2309-18.

35 Le Roux A, Kerdiles B, Walls D, et al. The Epstein-Barr virus determined nuclear antigens EBNA-3A, $-3 \mathrm{~B}$, and $-3 \mathrm{C}$ repress EBNA-2 mediated transactivation of the viral terminal protein 1 gene promoter. Virology 1994;205:596602.

36 Sample J, Henson EB, Sample C. The Epstein-Barr virus nuclear protein 1 promoter active in type I latency is autoregulated. I Virol 1992;66:4654-61.

37 Mannick JB, Cohen JI, Birkenbach M, et al. The Epstein-Barr virus nuclear protein encoded by the leader of the EBNA RNAs is important in B-lymphocyte transformation. F Virol 1991;65:6826-37.

38 Sinclair AJ, Palermo I, Peters G, et al. EBNA-2 and EBNA-LP cooperate to cause G0 to G1 transition during EBNA-LP cooperate to cause G0 to G1 transition during
immortalization of resting human B lymphocytes by immortalization of resting human B lymp

39 Cheng G, Baltimore D. TANK, a co-inducer with TRAF2 of TNF-and CD40L-mediated NF- $\mathrm{kB}$ activation. Genes Dev 1996;10:963-73.

40 Szekely L, Selivanova G, Magnusson KP, et al. EBNA-5, an Epstein-Barr virus-encoded nuclear antigen, binds to the retinoblastoma and p53 proteins. Proc Natl Acad Sci USA 1993;90:5455-9.

41 Wang D, Liebowitz D, Kieff E. An EBV membrane protein expressed in immortalized lymphocytes transforms established rodent cells. Cell 1985;34:831-40.

42 Baichwal VR, Sugden B. Transformation of Balb/3T3 cells by the BNLF-1 gene of Epstein-Barr virus. Oncogene 1988; 2:461-7.

43 Gregory CD, Dive C, Henderson S, et al. Activation of Epstein-Barr virus latent genes protects human B cells from death by apoptosis. Nature 1991;349:612-14

44 Henderson S, Rowe M, Gregory C, et al. Induction of bcl-2 expression by Epstein-Barr virus latent membrane protein protects infected B cells from programmed cell death. Cell 1991;65:1071-115.

45 Laherty CD, Hu MM, Opipari AW, et al. The Epstein-Barr virus LMP1 gene product induces A20 zinc finger protein expression by activating nuclear factor $\mathrm{\kappa B}$. 7 Biol Chem 1992;267:24157-60.

46 Eliopoulos AG, Stack M, Dawson CW, et al. Epstein-Barr virus encoded LMP1 and CD40 mediate IL-6 production in epithelial cells via an NF- $\kappa \mathrm{B}$ pathway involving TNFreceptor-associated factors. Oncogene 1997;14:2899-16.

47 Nakagomi H, Dolcetti R, Bejarano MT, et al. The EpsteinBarr-virus latent membrane protein-1 (LMP1) induces interleukin-10 production in Burkitt-lymphoma lines. Int $\mathcal{F}$
Cancer 1994;57:240-4.

48 Withdrawn.

49 Wilson JB, Weinberg W, Johnson R, et al. Expression of the BNLF-1 oncogene of Epstein-Barr virus in the skin of transgenic mice induces hyperplasia and aberrant expression of keratin 6. Cell 1990;61:1315-27.

50 Fahraeus R, Rymo L, Rhim JS, et al. Morphological transformation of human keratinocytes expressing the

51 Dawson CW, Rickinson AB, Young LS. Epstein-Barr virus latent membrane protein inhibits human epithelial cell differentiation. Nature 1990;344:777-80.

52 Huen DS, Henderson SH, Croom-Carter D, et al. The Epstein-Barr virus latent membrane protein (LMP1) mediates activation of NF- $\mathrm{kB}$ and cell surface phenotype via two effector regions in its carboxyl-terminal cytoplasmic domain. Oncogene 1995;10:549-60. 
53 Eliopoulos AG, Young LS. Activation of the cJun N-terminal kinase (JNK) pathway by the Epstein-Bar virus encoded latent membrane protein-1. Oncogene 1998 16:1731-42.

54 Eliopoulos AG, Gallagher NJ, Blake SMS, et al. Activation of the p38 mitogen activated protein kinase pathway by Epstein-Barr virus-encoded latent membrane protein 1 coregulates interleukin- 6 and interleukin- 8 production. $\mathcal{F}$ Biol Chem 1999;274:16085-96.

55 Gires O, Kohlhuber F, Kilger E, et al. Latent membrane protein 1 of Epstein-Barr virus interacts with JAK3 and activates STAT proteins. EMBO 7 1999;18:3064-73.

56 Izumi KM, Kieff ED. The Epstein-Barr virus oncogenic product latent membrane protein 1 engages the tumour necrosis factor receptor-associated death domain protein to mediate B lymphocyte growth transformation and activate NF-kB. Proc Natl Acad Sci USA 1997;94:12592-7.

57 Kaye KM, Izumi KM, Mosialos G, et al. The Epstein-Barr virus LMP1 cytoplasmic carboxy terminus is essential for B-lymphocyte transformation: fibroblast cocultivation complements a critical function within the terminal 155 residues. F Virol 1995;69:675-83.

58 Knecht H, Bachmann E, Brousset P, et al. Deletions within the LMP1 oncogene of Epstein-Barr virus are clustered in Hodgkin's disease and identical to those observed in nasopharyngeal carcinoma. Blood 1993;82:2937-42.

$59 \mathrm{Li} \mathrm{SN}$, Chang YS, Liu ST. Effect of a 10 amino acid deletion on the oncogenic activity of latent membrane protein 1 of Epstein-Barr virus. Oncogene 1996;12:2129-35.

60 Devergne O, Hatzivassiliou E, Izumi KM, et al. TRAF1, TRAF2, and TRAF3 effect NF-kB activation by an TRAF2, and TRAF3 effect NF- $\mathrm{KB}$ activation by an Epstein-Barr virus LMP1 domain important for B 108 .

61 Mosialos G, Birkenbach M, Yalamanchili R, et al. The Epstein-Barr virus transforming protein LMP1 engages signalling proteins for the tumour necrosis factor receptor family. Cell 1995;80:389-99.

62 Sandberg M, Hammerschmidt W, Sugden B. Characterisation of LMP1s association with TRAF1, TRAF2, and TRAF3. F Virol 1997;71:4649-56.

63 Eliopoulos AG, Blake SMS, Floettmann JE, et al. EpsteinBarr virus-encoded latent membrane protein 1 activates the INK pathway through it's extreme C-terminus via mechanism involving TRADD and TRAF2. I Virol mechanism involvin

64 Leonard WJ, O'Shea JJ. JAKS and STATS: biological implications. Annu Rev Immunol 1998;16:293-322.

65 Gires O, Zimber-Strobl U, Gonnella R, et al. Latent membrane protein 1 of Epstein-Barr virus mimics a constitutively active receptor molecule. EMBO f 1997;16:613140.

66 Floettmann JE, Rowe M. Epstein-Barr virus latent membrane protein-1 (LMP1) C-terminus activation region 2 (CTAR2) maps to the far C-terminus and requires oligomerisation for NF-אB activation. Oncogene 1997;15:1851-8.

67 Hatzivassilou E, Miller WE, Raab-Traub N, et al. A fusion of the EBV latent membrane protein-1 (LMP1) transmembrane domains to the CD 40 cytoplasmic domain is similar brane domains to the CD 40 cytoplasmic domain is similar to LMP1 in constitutive activation of epidermal growth factor receptor expression, nuclear factor $\mathrm{\kappa B}$, and
activated protein kinase. F Immunol 1998;3:1116-21.

68 Longnecker R, Kieff E. A second Epstein-Barr virus membrane protein (LMP2) is expressed in latent infection and co-localises with LMP1. F Virol 1990;64:2319-26.

69 Fruehling S, Longnecker R. The immunoreceptor tyrosinebased activation motif of Epstein-Barr virus LMP2A is essential for blocking BCR mediated signal transduction. Virology 1997;235:241-51.

70 Miller CL, Burkhardt AL, Lee JH, et al. Integral membrane protein 2 of Epstein-Barr virus regulates reactivation from latency through dominant negative effects on proteintyrosine kinases. Immunity 1995;2:155-66.

71 Miller CL, Lee JH, Kieff E, et al. Epstein-Barr virus protein LMP2A regulates reactivation from latency by negatively regulating tyrosine kinases involved in sLg-mediated signa transduction. Infect Agents Dis 1994;3:128-36.

72 Brielmeier M, Mautner J, Laux G, et al. The latent membrane protein 2 gene of Epstein-Barr virus is important for efficient B cell immortalization. $\mathcal{F}$ Gen Virol 1996;77:2807-18

73 Swaminathan S, Tomkinson B, Kieff E. Recombinant Epstein-Barr virus with small RNA (EBER) genes deleted transforms lymphocytes and replicates in-vitro. Proc Nat Acad Sci USA 1991;88:1546-50.

74 Clarke PA, Schwemmie M, Schickinger J, et al. Binding of Epstein-Barr virus small RNA EBER-1 to the doubleEpstein-Barr virus small RNA EBER-1 to the doublestranded RNA-activat

75 Clemens MJ. Functional significance of the Epstein-Barr virus-encoded small RNAs. EBV Report 1994;5:107-11.

76 Lerner MR, Andrews NC, Miller G, et al. Two small RNAs encoded by Epstein-Barr virus and complexed with protein are precipitated by antibodies from patients with lupus erythematosus. Proc Natl Acad Sci USA 1981;78:805-9.

77 Toczyski DP, Matera AG, Ward DC, et al. The Epstein-Barr virus (EBV) small RNA EBER1 binds and relocalises ribosomal protein L22 in EBV infected human B-lymphocytes. Proc Natl Acad Sci USA 1994;91:3463-7.

78 Bhat RA, Thimmappaya B. Two small RNAs encoded by Epstein-Barr virus can functionally substitute for the virusassociated RNAs in the lytic growth of adenovirus 5. Proc Natl Acad Sci USA 1983;80:4789-93.
79 Weiss LM, Strickler JG, Warnke RA, et al. Epstein-Barr viral DNA in tissues of Hodgkin's disease. Am 7 Pathol DNA in tissue

80 Staal SP, Ambinder R, Beschorner WE, et al. A survey of Epstein-Barr virus DNA in lymphoid tissue: frequent detection in Hodgkin's disease. Am f Clin Pathol 1989;91: $1-5$.

81 Herbst H, Niedobitek G, Kneba M, et al. High incidence of Epstein-Barr virus genomes in Hodgkin's disease. Am $\mathcal{f}$ Pathol 1990;137:13-18.

82 Wu TC, Mann RB, Charache P, et al. Detection of EBV gene expression in Reed-Sternberg cells of Hodgkin's disease. Int 7 Cancer 1990;46:801-4.

83 Barletta JM, Kingma DW, Charache P, et al. Rapid in situ hybridization for the diagnosis of latent Epstein-Barr virus hybridization for the diagnosis of latent
infection. Mol Cell Probes 1993:7;105-9.

84 Pallesen G, Hamilton-Dutoit SJ, Rowe M, et al. Expression of Epstein-Barr virus latent gene products in tumour cells of Hodgkin's disease. Lancet 1991;337:320-2.

85 Murray PG, Young LS, Rowe M, et al. Immunohistochemical demonstration of the Epstein-Barr virus-encoded latent membrane protein in paraffin sections of Hodgkin's disease. F Pathol 1992;166:1-5.

86 Brink AA, Dukers DF, van den Brule AJ, et al. Presence of Epstein-Barr virus latency type III at the single cell level in post-transplantation lymphoproliferative disorders and
AIDS related lymphomas. F Clin Pathol 1997;50:911-18.

87 Grasser F, Murray PG, Kremmer E, et al. Monoclonal antibodies directed against the Epstein-Barr virus encoded nuclear antigen 1: immmunohistological detection of EBNA1 in the malignant cells of Hodgkin's 84:3792-8.

88 Murray PG, Niedobitek G, Kremmer E, et al. In situ detection of the Epstein-Barr virus-encoded nuclear antigen 1 in oral hairy leukoplakia and virus-associated carcinomas. $\mathcal{F}$ Pathol 1996;178:44-7.

89 Niedobitek G, Kremmer E, Herbst H, et al. Immunohistochemical detection of the Epstein-Barr virus-encoded latent membrane protein 2A in Hodgkin's disease and infectious mononucleosis. Blood 1997;90:1664-72.

90 Murray PG, Constandinou CM, Crocker J, et al. Analysis of major histocompatibility complex class I, TAP expression, and LMP2 epitope sequence in Epstein-Barr virus-positive Hodgkin's disease. Immunity to EBV in healthy virus carriers. Blood 1998;92:2477-83.

91 Henle W, Henle G, Zajac BA, et al. Differential reactivity of human serums with early antigens induced by Epstein-Barr virus. Science 1970;169:188-90.

92 Moss DJ, Burrows SR, Khanna R, et al. Immune surveillance against Epstein-Barr virus. Semin lmmunol 1992;4:97-104.

93 Sheldon PJ, Papamichail M, Hemsted EH, et al. Thymic origin of atypical lymphoid cells in IM. Lancet 1973;I: 1153-5.

94 Moss DJ, Rickinson AB, Pope JH. Long-term T cell mediated immunity to Epstein-Barr virus in man. I. Complete regression of virus-induced transformation in cultures of seropositive donor leukocytes. Int 7 Cancer 1978;22:662-8.

95 Moss DJ, Rickinson AB, Pope JH. Long-term T cell mediated immunity to Epstein-Barr virus in man. III. Activation of cytotoxic T cells in virus-infected leucocyte cultures. Int f Cancer 1979;23:618-25.

96 Misko IS, Sculley TB, Schmidt C, et al. Composite response of naive $\mathrm{T}$ cells to stimulation with the autologous lymphoblastoid cell line is mediated by $\mathrm{CD}^{+}$cytotoxic $\mathrm{T}$ cell clones and includes an Epstein-Barr virus-specific component. Cell Immunol 1991;132:295-307.

97 Gavioli R, Kurilla M, de Campos-Lima PO, et al. Multiple HLA A11 restricted CTL epitopes of different immunogenicities in the Epstein-Barr virus encoded nuclear antigen-4 (EBNA4). $\mathcal{F}$ Virol 1993;67:1572-8.

98 Levitsky V, Zhang QJ, Levitskaya J, et al. The life span of major histocompatibility complex-peptide complexes inmajor histocompatibility complex-peptide complexes inof two class I-restricted cytotoxic T-lymphocyte epitopes in of two class I-restricted cytotoxic T-lymphocyte epitopes in
the Epstein-Barr virus nuclear antigen 4.7 Exp Med 1996; 183: E15-26.

99 de Campos-Lima PO, Gavioli R, Zhang QJ, et al. HLA-A 11 epitope loss isolates of Epstein-Barr virus from a highly A $11^{+}$population. Science 1993;260:98-100.

100 de Campos-Lima PO, Levitsky V, Brooks J, et al. T cell responses and virus evolution: Epstein-Barr virus isolates from highly HLA A11-positive populations carry mutations selectively involving anchor residues of A11-restricted CTL epitopes. F Exp Med 1994;179:1297-305.

101 Trivedi P, Masucci MG, Winberg G, et al. The EpsteinBarr virus encoded membrane protein LMP but not the nuclear antigen EBNA-1 induces rejection of transfected murine mammary carcinoma cells. Int $\mathcal{F}$ Cancer 1991;48: 794-800.

102 Khanna R, Burrows SR, Steigerwald-Mullen PM, et al. Isolation of cytotoxic T-lymphocytes from healthy seropositive individuals specific for peptide epitopes from Epstein-Barr virus nuclear antigen 1: implications for viral 633-7.

103 Levitskaya J, Coram M, Levitsky V, et al. Inhibition of antigen processing by the internal repeat region of the EpsteinBarr virus nuclear antigen-1. Nature 1995;375:685-8.

104 Lee SP, Thomas WA, Murray RJ, et al. HLA A2.1 restricted cytotoxic $\mathrm{T}$ cells recognizing a range of EpsteinBarr virus isolates through a defined epitope in laten membrane protein LMP2. f Virol 1993;67:7428-35. 
105 Sing A, Ambinder RF, Hong DJ, et al. Isolation of EpsteinBarr virus (EBV)-specific cytotoxic T lymphocytes that lyse
Reed-Sternberg cells: implications for immune-mediated therapy for Hodgkin's disease. Blood 1997;89:1978.

106 Nalesnik MA, Jaffe R, Starzl, et al. The pathology of post transplant lymphoproliferative disorders occurring in the setting of cyclosporine A-prednisone immunosuppression. Am $\mathcal{F}$ Pathol 1988;133:173-92.

107 Zutter MM, Martin PJ, Sale GE, et al. Epstein-Barr virus lymphoproliferation after bone marrow transplantation. Blood 1988;72:520-9.

108 Withersponn RP, Fisher LD, Schoch G, et al. Secondary cancers after bone marrow transplantation for leukemia or aplastic anemia. N Engl f Med 1989;321:784-9.

109 Crawford DH, Thomas JA, Janossy G, et al. Epstein-Barr virus nuclear antigen positive lymphoma after cyclosporin A treatment in patients with renal allograft. Lancet 1980;I: A treatmen

110 Rooney CM, Smith CA, Ng CYC, et al. Use of gene-modified virus-specific $\mathrm{T}$ lymphocytes to contro Epstein-Barr-virus-related lymphoproliferation. Lancet

111 Papadopoulos EB, Ladanyi M, Emanuel D, et al. Infusion of donor leukocytes to treat Epstein-Barr virus associated lymphoproliferative disorders after allogeneic bone marrow transplantation. N Engl f Med 1994;331:679-80

112 Heslop HE, Ng CYC, Smith CA, et al. Long term restoration of immunity against Epstein-Barr virus infection by adoptive transfer of gene-modified virus-specific $\mathrm{T}$ lymphocytes. Nat Med 1996;2:551-5.

113 Young L, Alfieri C, Hennessy K, et al. Expression of Epstein-Barr virus transformation-associated genes in tissues of patients with EBV lymphoproliferative disease. $N$ Engl f Med 1989;321:1080-5.

114 Cen H, Williams PA, McWilliams HP, et al. Evidence for restricted Epstein-Barr virus latent gene expression and anti-EBNA antibody response in solid organ transplant recipients with posttransplant lymphoproliferative disorders. Blood 1993;81:1393-403.

115 Murray PG, Swinnen LJ, Constandinou CM, et al. bcl-2 but not the EBV-encoded bcl-2 homologue, BHRF1, is commonly expressed in post-transplantation lymphoproliferative disorders. Blood 1996;87:706-11.

116 Knowles DM, Cesarman E, Chadburn A, et al. Correlative morphologic and molecular genetic analysis demonstrates three distinct categories of posttransplantation lymphoproliferative disorders. Blood 1995;85:552-65.

117 Polack A, Hortnagel K, Pajic A, et al. MYC activation renders proliferation of Epstein-Barr virus (EBV)transformed cells independent of EBV nuclear antigen 2 and latent membrane protein 1. Proc Natl Acad Sci USA 1996;93:10411-16.

118 Cesarman E, Chadburn A, Liu YF, et al. BCL-6 gene mutations in posttransplantation lymphoproliferative disorders predict response to therapy and clinical outcome. Blood 1998;92:2294-302.

119 Liebowitz D. Epstein-Barr virus and a cellular signaling pathway in lymphomas from immunosuppressed patients. N Engl F Med 1998;338:1413-21.

120 Rickinson AB. Epstein-Barr virus in action in vivo. $N$ Engl f Med 1998;338:1461-3.

121 Cen H, Breinig MC, Atchison RW, et al. Epstein-Barr virus transmission via the donor organs in solid organ
transplantation: polymerase chain reaction and restriction fragment length polymorphism analysis of IR2, IR3, and IR4. F Virol 1991;65:976-80.

122 Ho M, Miller G, Atchison RW, et al. Epstein-Barr virus infections and DNA hybridization studies in posttransplaninfections and DNA hybridization studies in posttransplanof primary infection. F Infect Dis 1985;152:876-86.

123 MacMahon EME, Glass JD, Hayward SD, et al. EpsteinBarr virus in AIDS-related primary central nervous system lymphoma. Lancet 1991;338:969-73.

124 Boyle MT, Sewell WA, Sculley TB, et al. Subtypes of Epstein-Barr virus in human immunodeficiency virusassociated non-Hodgkin lymphoma. Blood 1991;78:3004-11.

125 Cesarman E, Chang YI, Moore PS, et al. Kaposi's sarcoma associated herpesvirus-like DNA sequences in AIDS-
related body cavity based lymphomas. N Engl f Med 1995; 332:1186-91

126 Shibata M, Weiss LM, Nathwani BN, et al. Epstein-Barr virus in benign lymph-node biopsies from individuals infected with the human immunodeficiency virus is associated with concurrent or subsequent development of non-Hodgkin's lymphoma. Blood 1991;77:1527-33.

127 Carbone A, Tirelli U, Gloghini A, et al. Human immunodeficiency-virus-associated systemic lymphomas may be subdivided into two main types according to Epstein-Bar

128 Razzouk BI, Srinivas S, Sample CE, et al. Epstein-Barr virus DNA recombination and loss in sporadic Burkitt's lymphoma. F Infect Dis 1996;173:529-35.

129 Shiramizu B, Barriga F, Neequaye J, et al. Patterns of chromosomal breakpoint locations in Burkitt's lymphoma: relevance to geography and Epstein-Barr virus association. Blood 1991;77:1516-26.

130 Lam KMC, Syed N, Whittle H, et al. Circulating EpsteinBarr virus-carrying $\mathrm{B}$ cells in acute malaria. Lancet 1991;337:876-8.

131 Gregory CD, Rowe DM, Rickinson AB. Different EpsteinBarr virus (EBV) B cell interactions in phenotypically distinct clones of a Burkitt lymphoma cell line. $\mathscr{f}$ Gen Virol tinct clones of a Bur
132 Hatzubai A, Anafi M, Masucci MG, et al. Down-regulation of the EBV-encoded membrane protein (LMP) in Burkitt of the EBV-encoded membrane protein (
lymphomas. Int 7 Cancer $1987 ; 40: 358-64$.

133 Rowe M, Rowe DT, Gregory CD, et al. Differences in B cell growth phenotype reflect novel patterns of EpsteinBarr virus latent gene expression in Burkitt's lymphoma cells. EMBO f 1987;6:2743-51

134 Niedobitek G, Agathanggelou A, Rowe M, et al. Heterogenous expression of Epstein-Barr virus latent proteins in endemic Burkitt's lymphoma. Blood 1995;86:659-65.

135 Carbone A, Gloghini A. Expression of Epstein-Barr virus encoded latent membrane protein-1 in

136 McMichael A, Bodmer WF, eds. A new look at tumour immunology. New York: CSHL Press, 1992.

137 de Campos-Lima PO, Torsteinsdottir S, Cuomo L, et al. Antigen processing and presentation by EBV-carrying cell ines: cell-phenotype dependence and influence of the EBV-encoded LMP1. Int f Cancer 1993;53:856-62.

138 Khanna R, Burrows SR, Agaet V, et al. Endoplasmic reticulum signal sequence facilitated transport of peptide epitopes restore immunogenicity of an antigen processing defective tumor cell line. Int Immunol 1994;6:639-45.

139 Lombardi L, Newcomb E, Dalla-Favera R. Pathogenesis of Burkitt lymphoma: expression of an activated c-myc oncogene in lymphoblasts. Cell 1987;49:161-70.

140 Polack A, Hortnagel K, Pajic A, et al. c-myc activation renders proliferation of Epstein-Barr virus (EBV)transformed cells independent of EBV nuclear antigen 2 and latent membrane protein 1. Proc Natl Acad Sci USA 1996;93:10411-16.

$141 \mathrm{Qu} \mathrm{L}$, Rowe DT. Epstein-Barr virus latent gene expression in uncultured peripheral blood lymphocytes. F Virol 1992; 66:3715-24

142 Tierney RJ, Steven N, Young LS, et al. Epstein-Barr virus latency in blood mononuclear cells: analysis of viral gene ranscription during primary infection and in the carrier state. F Virol 1994;68:7374-85.

143 Shimizu N, Tanabe-Tochikiura A, Kuroiwa Y, et al. Isolation of Epstein-Barr virus (EBV)-negative cell clones from the EBV-positive Burkitt's lymphoma (BL) line Akata: malignant phenotypes of BL cells are dependent on EBV. F Virol 1994;68:6069-73.

144 Gutensohn N, Cole P. Epidemiology of Hodgkin's disease. Semin Oncol 1980;7:92-102.

145 Levine PH, Ablashi DV, Berard CW, et al. Elevated antibody titers to Epstein-Barr virus in Hodgkin's disease. Cancer 1971;27:416-21.

146 Mueller N, Evans A, Harris NL, et al. Hodgkin's disease and Epstein-Barr virus. Altered antibody pattern before diagnosis. N Engl f Med 1989;32:689-95.

147 Alexander FE, Daniel CP, Armstrong AA, et al. Case clustering, Epstein-Barr virus Reed-Sternberg cell status and herpes virus serology in Hodgkin's disease: results of a case control study. Eur f Cancer 1995;31A:1479-86.

148 Weiss LM, Strickler JG, Warnke RA, et al. Epstein-Barr viral DNA in tissues of Hodgkin's disease. Am $\mathcal{F}$ Pathol 1987;129:86-91.

149 Chang KL, Albujar PF, Chen Y-Y, et al. High prevalence of Epstein-Barr virus in the Reed-Sternberg cells of Hodg kin's disease occurring in Peru. Blood 1993;81:496-501.

150 Weinreb M, Day PJR, Niggli F, et al. The consistent association between Epstein-Barr virus and Hodgkin's disease in children in Kenya. Blood 1996;87:3828-36.

151 Anagnostopoulos I, Herbst H, Niedobitek G, et al. Demonstration of monoclonal EBV genomes in Hodgkin's disease and Ki-1-positive anaplastic large cell lymphoma by combined Southern blot and in situ hybridization. Blood 1989;74:810-16.

152 Deacon EM, Pallesen G, Niedobitek G, et al. Epstein-Barr virus and Hodgkin's disease: transcriptional analysis of virus latency in the malignant cells. F Exp Med 1993;177: 339-49.

153 Jarrett RF, Gallagher A, Jones DB, et al. Detection of EBV genomes in Hodgkin's disease: relation to age. $\mathcal{F}$ Clin Pathol $1991 ; 44: 844-8$

154 Armstrong AA, Alexander FE, Cartwright R, et al. Epstein-Barr virus and Hodgkin's disease: further evidence for the three disease hypothesis. Leukemia 1998;12: $1272-6$

155 Uccini S, Monardo F, Stoppacciaro A, et al. High frequency of Epstein-Barr virus genome detection in Hodgkin's disease of HIV-positive patients. Int 7 Cancer 1990;46:581-5.

156 Flavell K, Constandinou C, Lowe D, et al. Effect of material deprivation on Epstein-Barr virus infection in Hodgkin's disease in the West Midlands. Br f Cancer 1999;80: 604-8.

157 d'Amore F, Iohansen P, Houmand A, et al. Epstein-Barr virus genome in non-Hodgkin's lymphomas occurring in immunocompetent patients: highest prevalence in nonlymphoblastic T-cell lymphoma and correlation with a poor prognosis. Blood 1996;87:1045-55.

158 Borisch B, Hennig I, Laeng RH, et al. Association of the subtype 2 of the Epstein-Barr virus with T-cell nonHodgkin lymphoma of the midline granuloma type. Blood 1993;82:858-64.

159 Raab-Traub N, Flynn K. The structure of the termini of the Epstein-Barr virus as a marker of clonal cellular proliferation. Cell 1986;47:883-9.

160 Klein G. The relationship of the virus to nasopharyngeal carcinoma. In: Epstein MA, Achong BG, eds. The Epstein-
Barr virus. Berlin: Springer-Verlag, 1979:339-50. 
161 Weiss LM, Movahed LA, Butler AE, et al. Analysis of lymphoepithelioma and lymphoepithelioma-like carcinomas Pathol 1989;13:625-31.

162 Niedobitek G, Hansmann ML, Herbst H, et al. Epstein-Barr virus and carcinomas: undifferentiated carcinomas but not squamous cell carcinomas of the nasopharynx are regularly associated with the virus. $\mathcal{F}$ Pathol 1991;165:17-24.

163 Young LS, Dawson CW, Clark D, et al. Epstein-Barr virus gene expression in nasopharyngeal carcinoma. 7 Gen Virol 1988;69:1051-65.

164 Niedobitek G, Young LS, Sam CK, et al. Expression of Epstein-Barr virus genes and of lymphocyte activation molecules in undifferentiated nasopharyngeal carcinomas. Am 7 Pathol 1992;140:879-87.

165 Brooks L, Yao QY, Rickinson AB, et al. Epstein-Barr virus latent gene transcription in nasopharyngeal carcinoma cells: coexpression of EBNA1, LMP1, and LMP2 trancells: coexpression of EBNA1,
scripts. I Virol 1992;66:2689-97.

166 Gilligan K, Rajadurai P, Lin J-C, et al. Expression of the Epstein-Barr virus Bam HI A fragment in nasopharyngeal carcinoma: evidence for a viral protein expressed in vivo. $\mathcal{F}$ Circl 1991;65:6252-9.

167 Brooks L, Lear AL, Young LS, et al. Transcripts from the Epstein-Barr virus BamHI A fragment are detectable in all three forms of virus latency. F Virol 1993;67:3182-90.

168 Cochet C, Martel-Renoir D, Grunewald V, et al. Expression of the Epstein-Barr virus immediate early gene, BZLF1, in nasopharyngeal carcinoma tumor cells. Virology 1993;197:358-65

169 Zheng X, Yan 1, Nilsson B, et al. Epstein-Barr virus infection, salted fish and nasopharyngeal carcinoma. A casecontrol study in southern China. Acta Oncolog 1994;33: 867-72.

170 Mazeron MC. Value of anti-Epstein-Barr antibody detection in the diagnosis and management of undifferentiated carcinoma of the nasopharynx. Bull Cancer Radiother 1996; 83:3-7.

171 Raab-Traub N, Flynn K, Pearson G, et al. The differentiated form of nasopharyngeal carcinoma contains Epsteinated form of nasopharyngeal carcinoma con

172 Pathmanathan R, Prasad U, Chandrika G, et al. Undifferentiated, non-keratinising, and squamous cell carcinoma of the nasopharynx. Variants of Epstein-Barr virus-infected neoplasia. Am $\mathcal{F}$ Pathol 1995;146:1355-67.

173 Yeung WM, Zong YS, Chiu CT, et al. Epstein-Barr virus carriage by nasopharyngeal carcinoma in situ. Int $\mathcal{f}$ Cancer 1993;53:746-50.
174 Raab-Traub N, Gilligan K, Sato H, et al. EBV DNA structure and expression in EBV-induced proliferations. In: Ablashi DV, Faggioni A, Krueger GRF, et al, eds. Epstein-Barr virus and human disease. Clifton, NJ: Humana Press, 1988:85-98.

175 Sam CK, Brooks LA, Niedobitek G, et al. Analysis of Epstein-Barr virus infection in nasopharyngeal biopsies from a high nasopharyngeal carcinoma risk group. Int $\mathcal{f}$ Cancer 1993;53:957-62.

176 Ho JHC. Current knowledge of the epidemiology of nasopharyngeal carcinoma. In: Biggs P, de The G, Payne L, eds.

177 Fujii T, Kawai T, Saito K, et al. EBER-1 expression in thymic carcinoma. Acta Pathol fpn 1993;43:107-10.

178 Imai S, Koizumi S, Sugiura M, et al. Gastric carcinoma: monoclonal epithelial malignant cells expressing EpsteinBarr virus latent infection protein. Proc Natl Acad Sci USA 1994;91:9131-5.

179 Weinberg E, Hoisington S, Eastman AY, et al. Uterine cervical lymphoepithelial-like carcinoma. Absence of EpsteinBarr virus. Am f Clin Pathol 1993;99:195-9.

180 Shanmugaratnam K, Sobin LH. Histological typing of upper respiratory tract tumours. Geneva: WHO, 1978.

181 Shibata D, Weiss LM. Epstein-Barr virus-associated gastric adenocarcinoma. Am F Pathol 1992;140:769-74.

182 Gulley ML, Pulitzer DR, Eagan PA, et al. Epstein-Barr virus infection is an early event in gastric carcinogenesis virus infection is an early event in gastric carcinogenesis and is independent of bcl-2 express

183 Raab-Traub N, Rajadurai P, Flynn K, et al. Epstein-Barr virus infection in carcinoma of the salivary gland. $\mathcal{F}$ Virol 1991;65:7032-6.

184 Selves J, Bibeau F, Brousset P, et al. Epstein-Barr virus latent and replicative gene expression in gastric carcinoma. Histopathology 1996;28:121-7.

185 Niedobitek G, Herbst H, Young LS, et al. Epstein-Barr virus and carcinomas: expression of the viral genome in an undifferentiated gastric carcinoma. Diagn Mol Pathol 1992; 1:103-8.

186 Bonnet M, Guinebretiere JM, Kremmer E, et al. Detection of Epstein-Barr virus in invasive breast cancers. 7 Natl Cancer Inst 1990;91:1376-81.

187 Sugawara Y, Mizugaki Y, Uchida T, et al. Detection of Epstein-Barr virus (EBV) in hepatocellular carcinoma tissue: a novel EBV latency characterized by the absence of EBV-encoded small RNA expression. Virology 1999;256: 196-202. 